\title{
TERMOBAROMETRIA DA SUÍTE METAMÓRFICA VÁRZEA DO CAPIVARITA (RS): EMBASAMENTO DO CINTURÃO DOM FELICIANO
}

\author{
ANDRÉIA OLIVEIRA MONTEIRO DA SILVA ${ }^{1}$, CARLA CRISTINE PORCHER ${ }^{2}$, \\ LUIS ALBERTO DÁ VILA FERNANDES ${ }^{3}$ \& GILES DROOP ${ }^{4}$
}

\begin{abstract}
Abastract THERMOBAROMETRY OF THE VÁRZEA DO CAPIVARITA METAMORPHIC SUITE, (RS): BASEMENT OF THE DOM FELICIANO BELT Thermobarometric and structural geology investigation of rocks belonging to the Suíte Metamorfica Várzea do Capivarita (SMVC), unit cropping out along the eastern segment of the Dom Feliciano Belt (RS), have revealed that they were affected by two main metamorphic episodes. With the use of THERMOCALC Program it was possible to demonstrate that the older episode $\left(\mathrm{M}_{1}\right)$, syntectonic to the flat-lying shear zones with $\mathrm{E}-\mathrm{W}$ tectonic transport direction was developed under conditions of $740-790^{\circ} \mathrm{C}$ and pressures between $3-4 \mathrm{kbar}$, belonging, therefore, to the low $\mathrm{P} / \mathrm{T}$ baric type metamorphism. The younger metamorphic episode $\left(\mathrm{M}_{2}\right)$ and associated penetrative deformation of impure marbles were developed under amphibolite facies conditions and abundant fluids. The close spacial association and the perfect structural agreement between the Varzea do Capivarita Metamorphic Suit supracrustals rocks and the calc-alcaline gneissic rocks of the Arroio dos Ratos Complex, as the lower pressures of the $M_{1}$ metamorphism suggest that this could be cause by the intrusion warm.
\end{abstract}

Keywords: Dom Feliciano Belt, Várzea do Capivarita Suite, metamorphic petrology, geothermobarometry

Resumo O estudo das condições de metamorfismo das rochas da Suíte Metamórfica Várzea do Capivarita (SMVC), foi realizado através da utilização de métodos de geotermobarometria, apoiados por estudos de geologia estrutural e microtectônica. Foi possível demonstrar que essas rochas foram afetadas por dois episódios principais de metamorfismo. Utilizando-se o programa THERMOCALC foi possível determinar-se que o episódio mais antigo $\left(\mathrm{M}_{1}\right)$, registrado em todos os litotipos da SMVC, desenvolveu-se durante tectônica tangencial, com transporte tectônico E-W, sob condições de temperatura entre $740-790^{\circ} \mathrm{C}$ e pressões entre 3 e $4 \mathrm{kbar}$, caracterizando metamorfismo de baixa P/T. O episódio metamóifico mais novo $\left(\mathrm{M}_{2}\right)$, forma trama tectônica apenas nos mármores impuros e caracteriza-se por paragêneses minerais de fácies anfibolito médio e presença abundante de fluidos. A íntima associação espacial e a perfeita concordância estrutural entre as rochas supracrustais da Suíte Metamórfica Várzea do Capivarita e os gnaisses cálcio-alcalinos do Complexo Gnáissico Arroio dos Ratos, juntamente com as baixas pressões do metamorfismo $\mathrm{M}_{1}$ sugere que este pode ter sido influenciado pelo calor das intrusões.

Palavras-chaves: Cinturão Dom Feliciano, Suite Metamórfica Várzea do Capivarita, petrologia metamórfica, geotermobarometria

INTRODUÇÃO OEscudo Sul-rio-grandense é uma associação de rochas metamórficas, ígneas e sedimentares arqueanas a neoproterozóicas. Abrangendo quase a totalidade da sua área, ocorre o Cinturão Dom Feliciano, que representa o registro catazonal de um antigo orógeno, retratado por associações de rochas alongadas segundo NE (Fig. 1). Grande parte das unidades que afloram nesse cinturão são geneticamente relacionadas, ou foram tectonicamente aglutinadas durante diversos episódios responsáveis pela colagem orogênica no Neoproterozóico $(c f$. Fernandes et al. 1995a,b, Chemale Jr. et al. 1995).

Apesar dos estudos extensivos realizados nas últimas décadas (Fernandes et al 1995a,b, Babinski et al. 1994, 1996, Chemale Jr. et al. 1995), que possibilitaram melhor entendimento da evolução estrutural e geotectônica desse cinturão, permanecem diversas lacunas sobre a evolução anterior à aglutinação neoproterozóica. As maiores dificuldades para o entendimento da história inicial desse cinturão relacionam-se à carência de dados geocronológicos e acerca da evolução metamórfica das rochas interpretadas como embasamento desse cinturão, já que os dados existentes estão limitados essencialmente aos granulitos Santa Maria Chico e Gnaisses Encantadas (Hartmann 1998, Soliani Jr. 1986).

Embora essas sejam as unidades do embasamento mais conhecidas, trabalhos de geocronologia recentes (Babinski et al 1994, 1996, Leite et al. 1998, 2000, da Silva et al. 1999, 2000) confirmaram a presença de segmentos de idade paleoproterozóica em outras porções do Cinturão Dom Feliciano, particularmente na sua porção leste e central, onde os ortognaisses pertencentes ao Complexo Gnáissico Arroio dos Ratos (Fernandes et al. 1992) apresenta-

\footnotetext{
1 - Rua Dr. Campos Velho, 882/401, andreiaomonteiro@zipmail.com.br, CEP 90820-000, Porto Alegre

2 - Rua Cláudio Manoel da Costa,279, carla@if.ufrgs.br, CEP 91215-250, Porto Alegre

3 - Caixa Postal 15065, CEP 91501-970, Bairro Agronomia, ferna@if.ufrgs.br, Porto Alegre

4 - University or Manchester, Oxford Road, M 13 9PL, Manchester, UK
} 
ram idades U-Pb concórdia de $2.067 \pm 50$ (Leite et al. 1998,2000) e $1.538 \pm 7 \mathrm{Ma}$ (da Silva et al. 1999,2000 ), interpretadas como idades magmáticas. No entanto, dados geocronológicos recentes (Silva et al. em preparação) indicam idades neoproterozóicas para o metamorfismo de alto grau das rochas supracrustais objeto do presente estudo.

Este trabalho visa a caracterização das condições de metamorfismo dos eventos tectono-metamórficos que afetaram a crosta do Segmento Leste do Domínio Central do Cinturão Dom Feliciano (Fernandes et al. 2001), permitindo, assim, melhor entendimento da sua evolução tectônica. Na região de Encruzilhada do Sul, os ortognaisses do Complexo Gnáissico Arroio dos Ratos (CGAR) intrudem uma seqüência de rochas supracrustais de alto grau, chamada de Suíte Metamórfica Várzea do Capivarita (SMVC). Assim, por apresentar rochas favoráveis à obtenção de dados termobarométricos, a SMVC foi selecionada para esse estudo. Como demonstrado a seguir, este estudo permite uma nova pro- posição acerca dos ambientes tectônicos na época de formação da unidade considerada.

Geologia da Área de Estudo OCinturão Dom Feliciano é dividido nos Domínio Leste, Central e Oeste (Costa et al. 1995, Costa 1997, Fernandes et al. 1995a, b). Os segmentos estudados encontramse no Domínio Central (DC). Esse domínio é formado predominantemente por rochas crustais paleoproterozóicas, que podem ser agrupadas em (Fig. 1):

Segmento Leste - dominado por uma suíte TTG de gnaisses cálcio-alcalinos, com tetos pendentes e xenólitos de rochas supracrustais de alto grau (SMVC) alvo do presente estudo. Este segmento é interpretado na literatura como um fragmento de crosta continental, intrudida por granitóides cálcio-alcalinos paleoproterozóicos (Leite et al. 1998, 2000, da Silva et al. 1999, 2000 ) e cortados por zonas de cisalhamento transcorrente com magmatismo sintectônico (Fernandes \& Koester 1999). O evento

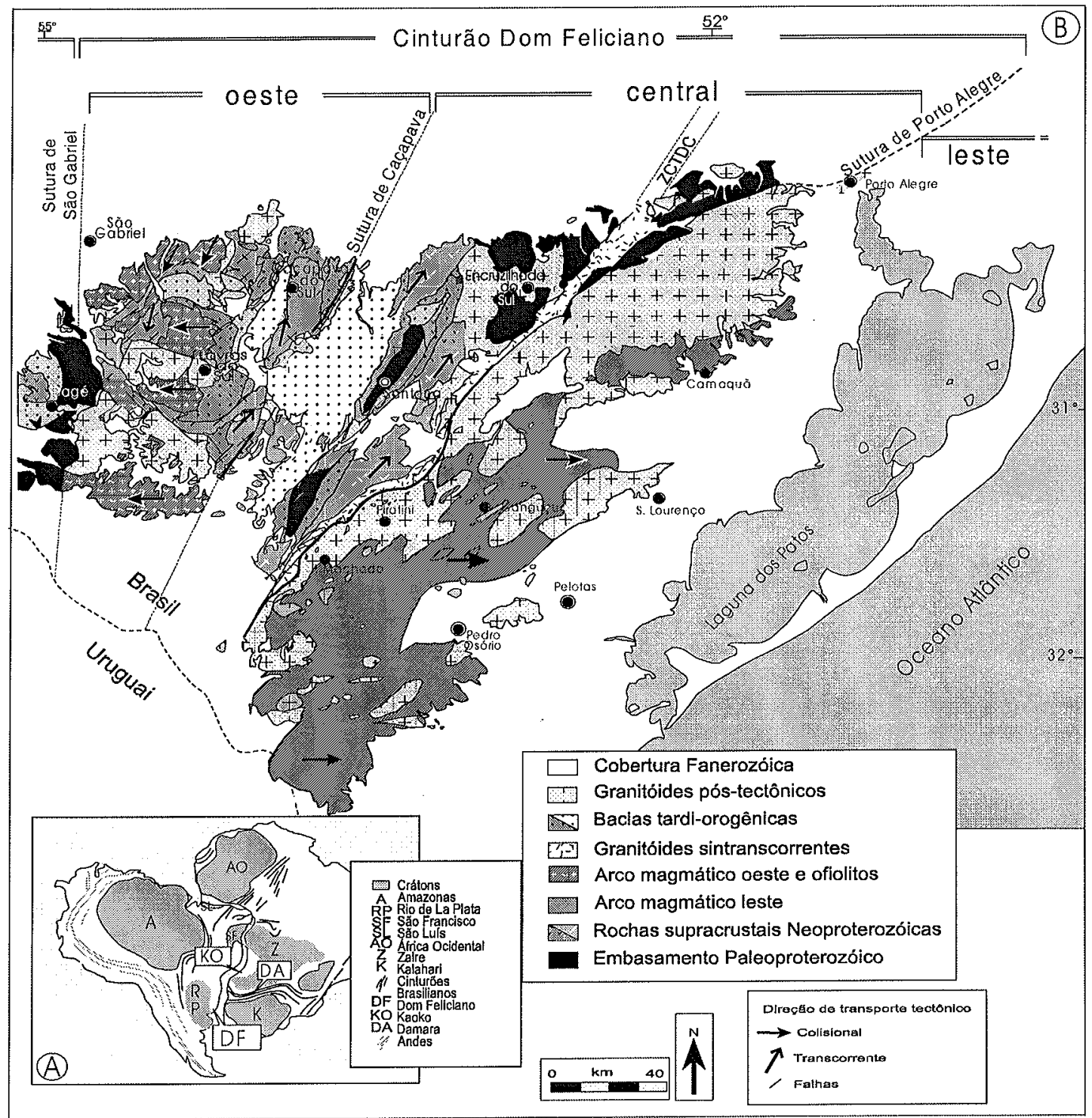

Figura 1 - Principais Associações Petrotectônicas do Cinturão Dom Feliciano. Modificado de Costa (1997). 
final estruturador desta crosta foi à intrusão de grandes volumes de magmas graníticos ao final do Neoproterozóico.

Segmento Oeste - apresenta uma intercalação tectônica de gnaisses do embasamento paleproterozóico com rochas supracrustais neoproterozóicas ao longo de zonas de cisalhamento sub-horizontais (Porcher \& Fernandes 1990).

Na região de Encruzilhada do Sul ocorrem associações de gnaisses de alto grau, com estruturas dúcteis formadas por fluxo tangencial na direção $\mathrm{E}-\mathrm{W}$, cortadas por zonas de cisalhamento transcorrentes NE do Sistema Dorsal de Canguçu (Fernandes \& Koester 1999). A intrusão de granitos cálcio-alcalinos alto-K a alcalinos, que constituem a maior parte da área de exposição, marca o final do Ciclo Brasiliano nessa região (Fig. 2).

Os gnaisses de alto grau, objeto do presente estudo, foram inicialmente descritos por Frantz et al. (1984), que os incluíram na unidade não formal denominada Complexo Metamórfico Várzea do Capivarita. Esse complexo é formado por paragnaisses aluminosos, calciossilicatados e quartzo-feldspáticos, intercalados com ortognaisses de composição granodiorítica a tonalítica. Incluíram ainda nesse complexo um grande corpo de anortosito (Anortosito Capivarita).

O Complexo Metamórfico Várzea do Capivarita foi posteriormente desmembrado em uma seqüência de paragnaisses de alto grau metamórfico, denominada Suíte Metamórfica Várzea do
Capivarita (SMVC), e ortognaisses cálcio-alcalinos, agrupados no Complexo Gnáissico Arroio dos Ratos (CGAR) (Fernandes et al. 1990). A SMVC aflora tipicamente em segmentos restritos e descontínuos geralmente circundados por ocorrências maiores de CGAR. Esse padrão de afloramento, em conjunto com o reconhecimento de relações de intrusão entre essas duas unidades e a coerência da atitude das estruturas dúcteis precoces entre os diversos segmentos da SMVC indica a presença de tetos pendentes, ou xenólitos no interior do CGAR (Fernandes et al. 1990).

Descriçäo Mesoscópica dos Tetos Pendentes da SMVC Considerando a forma descontínua de afloramento da SMVC, optou-se pela individualização das ocorrências mapeáveis em escala 1:25.000, caracterizando cada ocorrência com relação aos principais litotipos, paragêneses minerais e feições estruturais. Foram estudadas em detalhe três áreas de exposição das rochas da SMVC, informalmente denominados de segmentos Várzea do Capivarita, Cerro Partido e Arroio Canhão. Esses segmentos, além de apresentarem paragêneses minerais diagnósticas, importantes no estudo de terrenos metamórficos, podem ser individualizáveis numa escala adequada. Na Tabela 1 são apresentados os segmentos estudados, suas descrições petrográficas e suas respectivas paragêneses.

O segmento Cerro Partido é constituído por rochas metassedimentares clásticas e químicas intercaladas. O litotipo

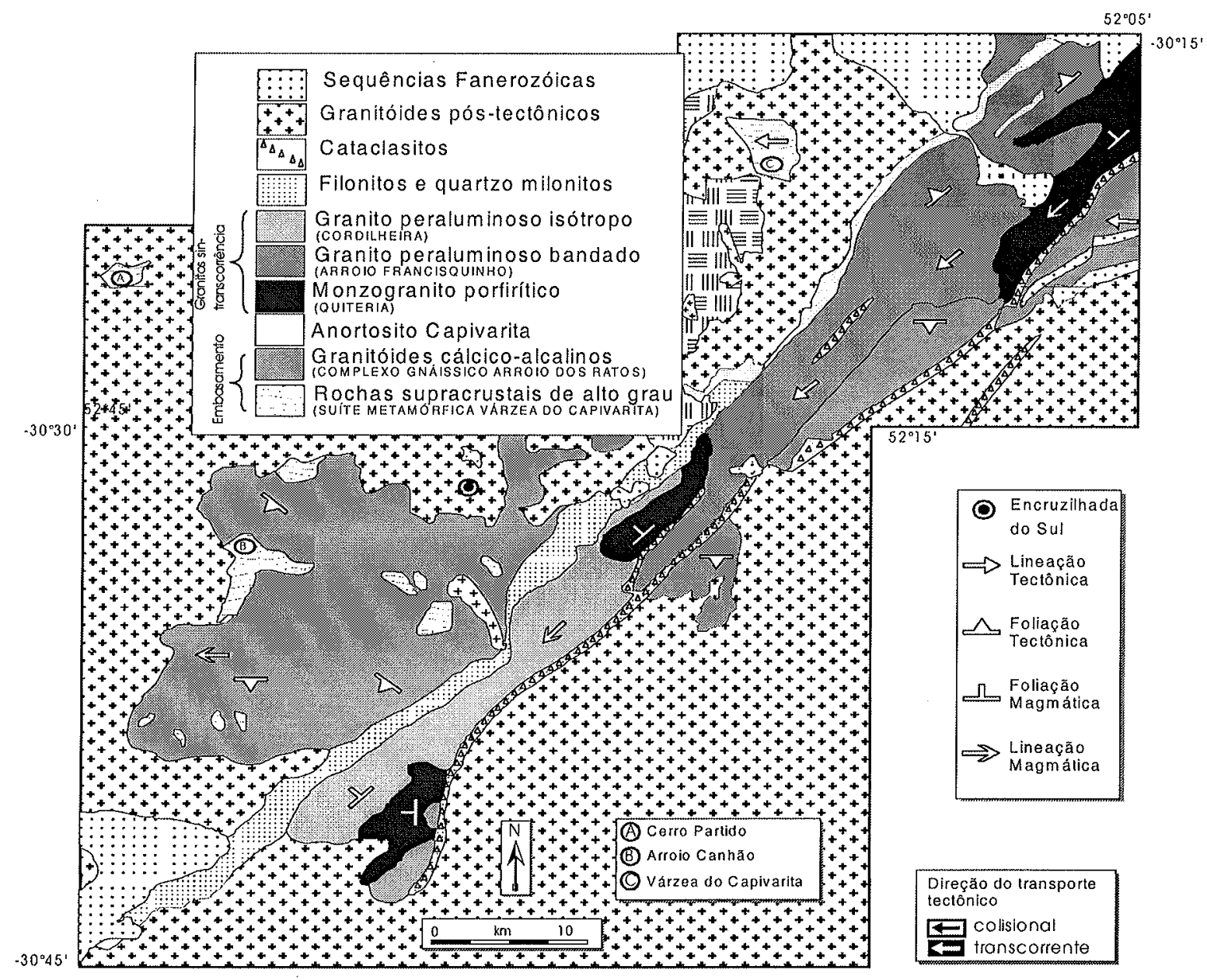

Figura 2 - Mapa de detalhe da área de estudo indicando as principais ocorrências da Suíte Metamórfica Várzea do Capivarita e Segmentos individualizados. Modificado de Fernandes e Koester (1999). 
dominante é um gnaisse pelítico com granada e cordierita. Em menor proporção ocorrem boudins de gnaisse calciossilicatado e bandas de gnaisse máfico, dispostos paralelamente ao bandamento do gnaisse pelítico. Nesse segmento ocorrem grandes volumes dos ortognaisses do CGAR.

O gnaisse pelítico apresenta coloração cinza-escuro e granulação fina, com bandamento composicional bem desenvolvido, marcado pela alternância de bandas máficas e félsicas. As bandas máficas do gnaisse pelítico têm espessura de 1 a $5 \mathrm{~cm}$, apresentando granada, biotita, cordierita e espinélio. As bandas félsicas têm 1 a 2 $\mathrm{cm}$ de espessura, sendo ricas em quartzo, feldspato potássico e plagioclásio, que por vezes marcam bandamento interno milimétrico descontínuo e lenticular com limites difusos.

O gnaisse pelítico apresenta, ainda, veios félsicos de espessura centimétrica, com granulação média a grossa, compostos por quartzo e feldspato potássico com ocorrência limitada de plagioclásio. Esses veios têm limites abruptos e pontiagudos e frequientemente cortam o bandamento gnáissico. Na interface gnaisse /veio ocorrem comumente porfiroblastos de granada. As características observadas são comuns em leucossomas gerados por fusão parcial de gnaisses pelíticos (Ashworth \& McLellan 1985), sendo a presença dos porfiroblastos de granada no interior e nos limites das lentes leucocráticas indicativas de reação de fusão parcial incongruente em ausência de fluido.

O gnaisse calciossilicatado ocorre como lentes boudinadas de espessuras variáveis (de 0.3 até 0.7 metros), intercaladas com o gnaisse pelítico e o gnaisse máfico. Apresentam coloração esverdeada, granulação média a fina e bandamento milimétrico interno marcado pela alternância de bandas máficas, ricas em clinopiroxênio e bandas félsicas, ricas em quartzo e plagioclásio. $\mathrm{O}$ clinopiroxênio está orientado e o quartzo ocorre como fitas, estando ambos paralelos ao bandamento do gnaisse pelítico. A presença de gnaisse calciossilicatado interdigitado no gnaisse pelítico sugere que essas lentes ricas em cálcio formaram-se por uma mistura de sedimentos ricos em argilas e carbonatos, gerados pela combinação de sedimentação química e clástica dentro do ambiente deposicional original.

O gnaisse máfico ocorre como lentes descontínuas, de espessura milimétrica a centimétrica, dobradas isoclinalmente. Essa rocha apresenta coloração escura e granulação muito fina. É formada por biotita, quartzo, plagioclásio e ortopiroxênio. O gnaisse máfico é interpretado como níveis mais ricos em sedimentos clásticos (arenosos) intercalados a sedimentos químicos e argilas marinhas.

O segmento Várzea do Capivarita é composto por mármores puros com calcita e dolomita e mármores impuros, ricos em silicatos (e.g. anfibólios, clinopiroxênios, olivina). Em escala mesoscópica, os mármores impuros mostram bandas composicionais $\left(\mathrm{S}_{0}\right)$ contínuas e homogêneas, cuja espessura varia desde alguns centímetros até poucos metros. O bandamento é marcado pela alternância de bandas máficas com flogopita e olivina e bandas félsicas compostas predominantemente por dolomita ( \pm calcita). Podem ocorrer ainda bandas claras boudinadas, ricas em diopsídio e pargasita, intercaladas com bandas de pequena espessura ricas em flogopita e olivina.

Nos mármores puros o bandamento composicional é representado por intercalações de bandas ricas em dolomita com bandas ricas em calcita. Comumente ocorrem boudins de dolomita, circundados por auréolas de aproximadamente $20 \mathrm{~cm}$ de espessura, com porfiroblastos de olivina (serpentinizada), por vezes intercrescidos com flogopita e calcita. Essas auréolas de forsterita provavelmente representam zonas de reação geradas pela percolação de fluidos ricos em $\mathrm{H}_{2} \mathrm{O}$ (Bucher \& Frey 1994).

O segmento Arroio Canhão é formado por gnaisses calciossilicatados, de coloração verde, granulação fina e bandamento composicional regular, marcado pela alternância de bandas félsicas e bandas máficas, com espessuras milimétricas a centimétricas. A composição mineral desses gnaisses é bastante variada. Nas bandas félsicas podem ocorrer calcita, quartzo, plagioclásio, escapolita e feldspato potássico. Os níveis máficos podem apresentar clinopiroxênio, biotita e granada. As diferentes composições do bandamento refletem variações composicionais originais da sedimentação predominantemente química.

Microtectônica Em escala microscópica, a principal trama identificada nos litotipos da SMVC encontra-se representada pelo bandamento gnáissico composto $\left(S_{0} / S_{1}\right)$. As paragêneses metamórficas dominantes atingiram equilíbrio durante pico térmico de alta temperatura $\left(M_{1}\right)$ após a formação de $S_{1}$, por recristalização estática, como indicado pela trama granoblástica bem desenvolvida em todas as amostras e ausência de evidências de deformação intracristalina. A presença de feições de reação localizadas (e.g. mirmequitos) entre as fases das paragêneses principais indica a ocorrência de retrogressão com participação limitada de fluidos $\left(\mathrm{M}_{2}\right)$, localizadamente acompanhada de formação de nova trama.

No segmento Cerro Partido, a paragênese $M_{1}$ dos gnaisses pelíticos é formada por quartzo + biotita + plagioclásio + feldspato potássico + cordierita + granada + espinélio. As bandas félsicas são ricas em quartzo e feldspatos, com textura granoblástica equigranular interlobada (Fig. 3a). As bandas máficas, ricas em

Tabela 1-Litotipos e paragêneses dos segmentos de Suíte Metamórfica Várzea do Capivarita. Abreviações Minerais de Kretz (1994).

\begin{tabular}{|l|l|l|}
\hline \multicolumn{1}{|c|}{ Unidade } & \multicolumn{1}{|c|}{ Litotipos } & \multicolumn{1}{c|}{ Paragêneses Diagnósticas } \\
\hline Segmento Cerro Partido & Gnaisse Pelítico & Grt + Crd + Bt + Kfs + PI + Qtz $\pm \mathrm{Sp}+$ Sill \\
\hline & Gnaisse Máfico & $\mathrm{Opx}+\mathrm{Cpx}+\mathrm{Pl}+\mathrm{Qtz} \pm \mathrm{Bt}$ \\
\hline & Gnaisse Calciossilicatado & $\mathrm{Cpx}+\mathrm{Pl}+\mathrm{Qtz}+\mathrm{Bt} \pm$ esfeno \\
\hline Segmento Arroio Canhão & Gnaisse Calciossilicatado & $\mathrm{Cpx}+\mathrm{Pl}+\mathrm{Qtz}+$ esfeno \\
& & $\mathrm{Cpx}+\mathrm{Pl}+\mathrm{Kfs}+\mathrm{Qtz}+$ esfeno \\
& & $\mathrm{Cpx}+\mathrm{Scp}+\mathrm{Pl}+\mathrm{Kfs}+\mathrm{Qtz}+$ esfeno \\
& & $\mathrm{Cpx}+\mathrm{Scp}+\mathrm{Qtz}+\mathrm{Cal} \pm \mathrm{Grs}$ \\
& & $\mathrm{Cpx}+\mathrm{Pl}+\mathrm{Hbl}+\mathrm{Qtz}+$ esfeno \\
\hline Segmento Várzea do Capivarita & Mármores Puros & $\mathrm{Cal}+\mathrm{Dol} \pm \mathrm{Ol}$ \\
\hline & Mármores Impuros & $\mathrm{Cal}+\mathrm{Phl}+\mathrm{Ol}$ \\
& & $\mathrm{Cpx}+\mathrm{Tre}+\mathrm{Cal}$ \\
\hline
\end{tabular}


biotita, granada e cordierita, tipicamente apresentam agregados de biotita com textura lepidoblástica. As lentes de leucossoma são compostas por quartzo + feldspato potássico + granada \pm plagioclásio \pm biotita, com textura granoblástica poligonal. A granulação média a grossa das lentes de leucossoma contrasta com a textura fina do gnaisse pelítico.

Três gerações de granada foram reconhecidas nos gnaisses pelíticos. A granada mais antiga (Grt) é circundada pela foliação e exibe sombra de pressão com crescimento de quartzo e biotita (Fig. 3c). São porfiroblastos subidioblásticos, de até $8 \mathrm{~mm}$, com limites arredondados e inclusões de quartzo, biotita, feldspatos e, por vezes, cordierita.

A granada Grt ${ }_{2}$ é nitidamente pós-tectônica, truncando a foliação. São porfiroblastos euédricos, de 0,2 a $2 \mathrm{~mm}$, com contatos retos (Fig. 3b). Em algumas amostras, Grt ${ }_{2}$ ocorre com textura esqueletal sobre agregados de biotita $\left(\mathrm{Bt}_{1}\right)$, indicando rápido aquecimento durante o crescimento destes porfiroblastos. Essa granada apresenta raras inclusões (e.g. biotita e cordierita) e ocorre em todas as lâminas de gnaisse pelítico descritas.

A granada $\mathrm{Grt}_{3}$ ocorre como porfiroblastos poiquiloblásticos, nas proximidades e no interior das bandas e lentes de leucossoma. São porfiroblastos subidioblásticos, de até $5 \mathrm{~mm}$, com contatos lobados e cúspides. Exibem inclusões de opacos e formam agregados intercrescidos com quartzo (Fig. 3d).

Foram identificadas três gerações de biotita. $\mathrm{A}$ biotita $\mathrm{Bt}$ forma agregados lepidoblásticos com lamelas avermelhadas de $2,5 \mathrm{~mm}$. Essa biotita é observada apenas em algumas amostras, mas quando presente, representa cerca de $15 \%$ da composição modal da rocha.

A biotita $\mathrm{Bt}_{2}$, encontrada em todas as amostras dos gnaisses pelíticos (Figs. 3b, 3e), caracteriza-se por seu tamanho diminuto $(0,02 \mathrm{~mm})$ e por sua orientação preferencial paralela à orientação das bandas. Ao contrário das $\mathrm{Bt}_{1}$, essa biotita representa no máximo 7\% da composição modal da rocha.

$\mathrm{A}$ biotita $\mathrm{Bt}_{3}$ ocorre como pequenos grãos $(<0,5 \mathrm{~mm})$ sem orientação preferencial, que ocorrem como intercrescimentos retrogressivos ao redor de porfiroblastos de granada Grt (Fig. 3c). Não são abundantes nos gnaisses pelíticos, sendo encontrada apenas em duas amostras.

A cordierita ocorre em duas formas distintas, como porfiroblastos $\left(\mathrm{Cdr}_{1}\right)$ e como agregados granoblásticos alongados paralelos à $\mathrm{S}_{1}$ $\left(\mathrm{Cdr}_{2}\right)$ (Fig. 3e). Os porfiroblastos são subédricos, com dimensões de até $1 \mathrm{~mm}$. Estão intensamente alterados para pinita ou muscovita - óxido de ferro, e tem ocorrência restrita. Os agregados granoblásticos são formados por grãos poligonais de dimensão inferior a $1 \mathrm{~mm}$, e ocorrem de forma mais abundante do que os porfiroblastos de cordierita.

O espinélio verde (hercinita) ocorre sempre sobre a cordierita, geralmente intercrescido com quartzo, e mais raramente, com silimanita (Fig. 3e). As feições microestruturais acima descritas permitem a determinação da paragênese mineral de pico metamórfico $M_{1}$ dos gnaisses pelíticos, que é representada por duas paragêneses mineralógicas distintas, condicionadas à composição da banda onde ocorre:

Paragênese 1: Ocorre nas bandas ricas em $\mathrm{Mg}$, sendo representada por granada + biotita + quartzo + feldspato potássico + plagioclásio + cordierita \pm fusão.

A paragênese 1 é formada pela reação descontínua (equação (1)) (Bucher \& Frey 1994):

$$
\mathrm{Bt}+\mathrm{Sil}+\mathrm{Qtz}=\mathrm{Crd}+\mathrm{Grt}+\mathrm{Kf}+\mathrm{H}_{2} \mathrm{O}(1)
$$

Que é diagnóstica de alto grau metamórfico em gnaisses pelíticos com cordierita. Essa paragênese ocorre em terrenos de baixa $\mathrm{Pe}$ alta T, em condições de $700 \pm 50^{\circ} \mathrm{C}$ e pressões de 2 a 5 kbar, diagnósticas da transição do fácies anfibolito superior para granulito (Bucher \& Frey 1994).

Paragênese 2: Ocorre nas bandas ricas em Fe, sendo representada por $\mathrm{Grt}+\mathrm{Bt}+\mathrm{Kfs}+\mathrm{Pl}+\mathrm{Spl} \pm \mathrm{Qtz} \pm \mathrm{Sil} \pm$ fusão. Essa paragênese é formada pela equação (2):

$$
\text { FeCrd }=\text { Herc }+ \text { Sill }+ \text { Qtz (2) }
$$

Estudos experimentais indicam que o crescimento de almandina cessa a $775^{\circ} \mathrm{C}$ de temperatura, e a $2.9 \mathrm{kbar}$ e $775^{\circ} \mathrm{C}$ a hercinita cresce, indicando que a partir desta temperatura a cordierita rica em Fe quebra para hercinita, silimanita e quartzo (Holdaway \& Lee 1977). A reação de quebra da $\mathrm{Fe}-\mathrm{Crd}$, equação (2) tem seu campo de estabilidade acima de $768^{\circ} \mathrm{C}$ em pressões de 2 a $4 \mathrm{kbar}$ (Holdaway \& Lee 1977). O intervalo de temperatura de estabilidade da paragênese 2, assim como a presença do espinélio que indica redução da $\mathrm{X}_{\mathrm{H} 2 \mathrm{O}}$ (Whittington et al. 1998), o que caracteriza condições metamórficas de fácies granulito.

A reação de quebra da $\mathrm{Fe}$-cordierita não ocorre nas bandas ricas em $\mathrm{Mg}$ porque nessas bandas a cordierita é rica em $\mathrm{Mg}$ cordierita, aumentando o limite de estabilidade da paragênese 1 .

Desta forma, conclui-sc que a paragênese $M_{1}$ dos gnaisses pelíticos da SMVC, tanto nas bandas ricas em Fe quanto nas composições ricas em $\mathrm{Mg}$, indicam redução da $\mathrm{P}_{\mathrm{H} 2 \mathrm{O}}$ do sistema, temperaturas entre 750 e $780^{\circ} \mathrm{C}$ e pressões entre 3 e $5 \mathrm{kbar}$, condições típicas da transição do fácies anfibolito superior/granulito, e que caracterizam um metamorfismo de baixa $P / T$.

A paragênese mineral $M_{1}$ no gnaisse máfico é representada por $\mathrm{Qtz}+\mathrm{Pl}+\mathrm{Bt} \pm \mathrm{Cpx} \pm \mathrm{Opx}$. Esse litotipo caracteriza-se pela presença de porfiroblastos de ortopiroxênio e clinopiroxênio imersos em matriz fina de textura granoblástica composta por quartzo, plagioclásio e clinopiroxênio. A principal feição retrogressiva é a formação de anfibólio sobre ortopiroxênio, que indica entrada de fluidos em temperaturas inferiores às da paragênese de mais alta temperatura.

O ortopiroxênio característico desse litotipo é hiperstênio, ocorrendo como porfiroblastos idioblásticos a subidioblásticos, de no máximo $2 \mathrm{~mm}$, formando textura nematoblástica incipiente. São freqüentes as ocorrências de pequenos núcleos rosados no interior dos porfiroblastos, representando exsoluções de clinopiroxênio. Grande parte dos porfiroblastos está total ou parcialmente substituído por anfibólio (actinolita), restando apenas pequenos núcleos inalterados de ortopiroxênio e clinopiroxênio.

O clinopiroxênio desse gnaisse é diopsídio e ocorre sob três formas texturalmente distintas: (1) porfiroblastos individuais subédricos (»2 $\mathrm{mm}$ ) com contatos irregulares e discreta textura nematoblástica, dispostos paralelamente a $S_{1}$; (2) pequenos cristais idioblásticos $(<1 \mathrm{~mm})$ com contatos arredondados, compondo a matriz do gnaisse; e (3) lamelas de exsolução em porfiroblastos de ortopiroxênio.

A biotita ocorre como cristais subidioblásticos de $1 \mathrm{~mm}$. Freqüentemente formam agregados em contato com os porfiroblastos de piroxênio. A paragênese mineral $M_{1}$ no gnaisse máfico é representada por $\mathrm{Cpx}+\mathrm{Opx}+\mathrm{Pl} \pm \mathrm{Qtz} \pm \mathrm{Bt}$. Essa paragênese é característica de condições de fácies granulito, que em rochas máficas é marcado pela primeira ocorrência de ortopiroxênio, através da reação de desidratação progressiva, equação (3) (Spear 1993):

$$
\mathrm{Hbl}+\mathrm{Qtz}=\mathrm{Opx}+\mathrm{Cpx}+\mathrm{Pl}+\mathrm{H}_{2} \mathrm{O}(3)
$$

Estudos experimentais (Spear 1981) indicam que essa reação de quebra da hornblenda inicia a partir de $775^{\circ} \mathrm{C}$ (olivina toleíto - 
tamponamento QFM), e a hornblenda desaparece por volta de $900^{\circ} \mathrm{C}$. Desta forma, conclui-se que a paragênese $M_{1}$ dos gnaisses máficos da SMVC, indicam redução da $\mathrm{P}_{\mathrm{H} 2 \mathrm{O}}$ do sistema, temperaturas entre 775 e $800^{\circ} \mathrm{C}$ e pressões baixas, devido à ausência de granada (Spear 1993).

Nos gnaisses calciossilicatados do segmento Arroio Canhão as principais paragêneses de pico metamórfico $\left(M_{1}\right)$ reconhecidas são: (i) $\mathrm{Cpx}+\mathrm{Pl}+\mathrm{Qtz}+$ esfeno, (ii) $\mathrm{Cpx}+\mathrm{Pl}+\mathrm{Kf}+\mathrm{Qtz}+$ esfeno, (iii) $\mathrm{Cpx}+\mathrm{Scp}+\mathrm{Pl}+\mathrm{Kf}+\mathrm{Qtz}+$ esfeno, (iv) $\mathrm{Cpx}+\mathrm{Scp}+\mathrm{Qtz}+\mathrm{Cal}$ ( (v)
$\mathrm{Cpx}+\mathrm{Pl}+\mathrm{Hbl}+\mathrm{Qtz}+$ esfeno. Esses gnaisses apresentam granulação fina a média, com textura granoblástica poligonal, indicando equilíbrio térmico e recristalização estática. Microestruturas como fitas de quartzo sem extinção ondulante e matriz granoblástica com quartzo e plagioclásio sugerem a atuação de processos de recuperação.

A presença de escapolita em diferentes amostras analisadas sugere condições de pico metamórfico superiores a $775^{\circ} \mathrm{C}$. Estudos experimentais (Ellis 1978, Harley \& Buick 1992) estimam valo-

\section{(a)}

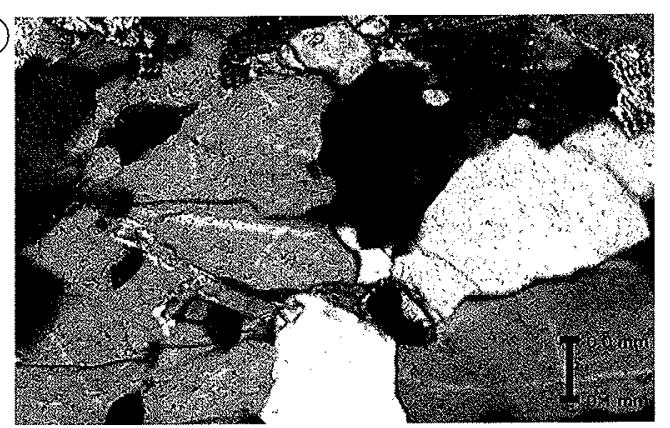

(C)

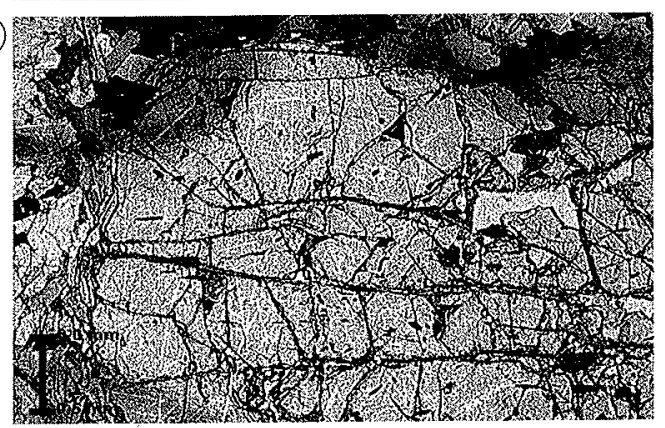

(e)

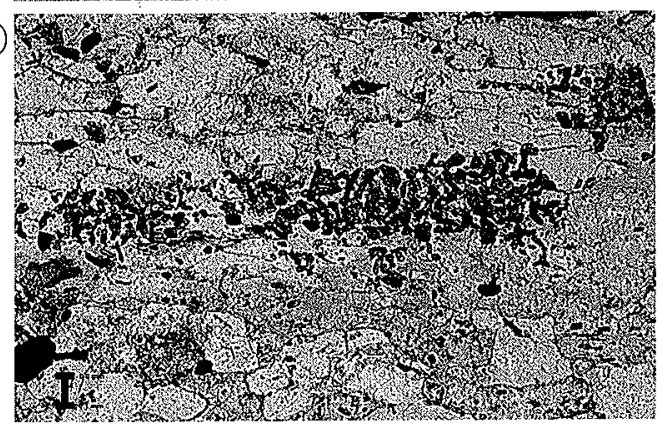

(9)

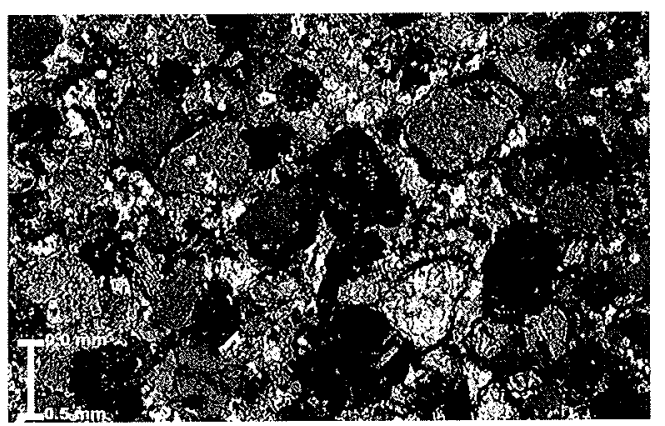

(b)

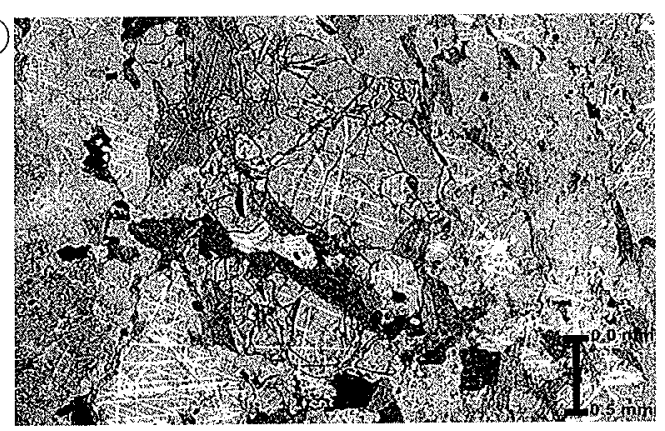

(d)

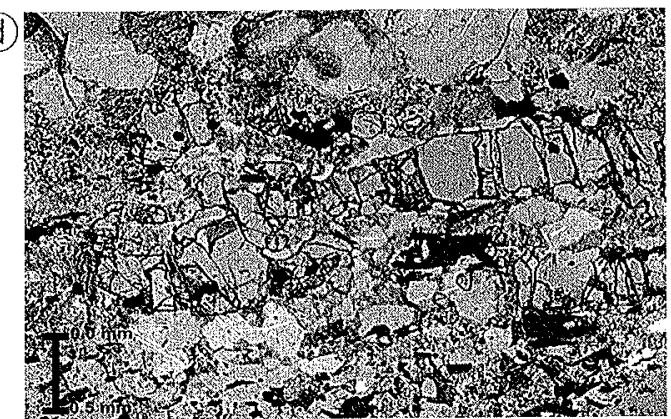

(f)

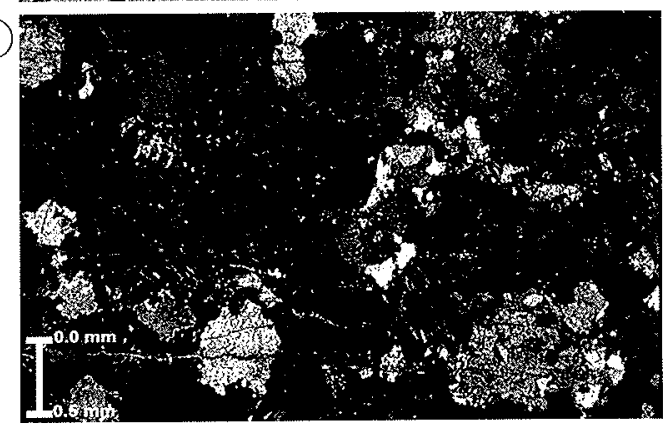

(b)

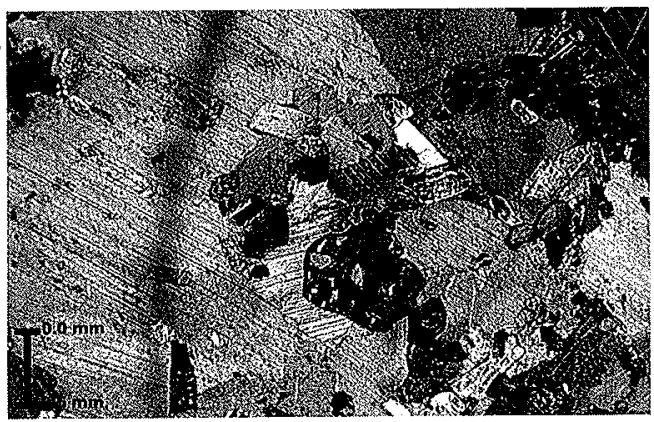

Figura 3 - Feições microestruturais da SMVC (escala na foto). Gnaisse Pelítico (a) Banda félsica com textura granoblástica equigranular interlobada. (b) Grt em contato com Bt ${ }_{2}(c) G r t$, em contato com lentes de leucossoma. (d) porfiroblastos de Grt, circundado por Bt. (e) porfiroblastos de Crd com intercrescimentos de $S p+$ Sil. Gnaisse calciossilicatado $(f)$ Grs poiquiloblástica englobando cristais de Cal, Qtz e Scp, sem Cpx. (g) cristais de Scp envoltos por coronas de Grs, com intercrescimentos de Qtz + Cal. Mármore impuro (h) banda máfica com $\mathrm{Cal}+\mathrm{Phl}+$ Ol em arranjos granoblásticos. Abreviações minerais de Kretz (1994). 
res de temperatura de $875^{\circ} \mathrm{C}$ para a reação de formação da escapolita com $\mathrm{Me}_{100}$, independente da pressão (Goldsmith \& Newton 1977), equação (4). A diminuição do componente meionita diminui a temperatura de formação da escapolita.

$\mathrm{An}+\mathrm{Cal}=\mathrm{Scp}(4)$

A paragênese de mais alta temperatura apresenta feições localizadas de reação em bandas de diferente composição, tais como: (i) coronas de Grs ao redor de cristais de Scp, coexistindo com calcita e quartzo (Fig. 3g, equação (5)) (ii) porfiroblastos poiquiloblásticos de Grs englobando cristais de Scp, Qtz e Cal (Fig. 3f, equação (6)). $\mathrm{Scp}+\mathrm{Cal}+\mathrm{Qtz}=\mathrm{Grs}+\mathrm{CO}_{2}(5)$

$\mathrm{Scp}+\mathrm{Cal}+\mathrm{Qtz}+\mathrm{Hd}=\mathrm{Grt}+\mathrm{CO}_{2}(6)$

A textura (i) foi interpretada anteriormente em termos de decréscimo da $\mathrm{X}_{\mathrm{CO} 2}$ ou do resfriamento com diminuição da $\mathrm{X}_{\mathrm{CO} 2}$ (Schenk 1984, Frisch 1988), em granulitos de Serre Massif (Schenk 1984) e Ellesmere-Devon Island (Frisch 1988). Entretanto estudos posteriores mostram que esta textura pode ser produzida em uma descompressão acompanhada por menor resfriamento, sem necessitar de quaisquer modificações na $X_{\mathrm{CO} 2}$ (Harley \& Buick 1992).

A textura (ii), desenvolvida pela equação (6), envolve o consumo de clinopiroxênio e escapolita é uma reação de decarbonização em alta T. O aumento do contcúdo de andradita da granada indica aumento da atividade de $\mathrm{O}_{2}$ (Schenk 1984).

As demais texturas observadas, representadas por: (iii) substituição de Pl por Zo, equação (7), (iv) porfiroblastos de cpx circundados por coronas simplectíticas de Amph + Cal + Qtz, equação (8), desenvolvem-se durante a trajetória retrogressiva do gnaisse calciossilicatado:

$$
\begin{aligned}
\mathrm{Scp}+\mathrm{H}_{2} \mathrm{O} & =\mathrm{Zo}+\mathrm{CO}_{2}(7) \\
\mathrm{Di}+\mathrm{H}_{2} \mathrm{O}+\mathrm{CO}_{2} & =\mathrm{Tr}+\mathrm{Cal}+\mathrm{Qtz}(8)
\end{aligned}
$$

As equações (7) e (8) são reações geradas pelo efeito da retrogressão de fácies anfibolito, através do influxo de $\mathrm{H}_{2} \mathrm{O}$ como uma fase fluida, dentro de um campo de temperatura em torno de $600^{\circ} \mathrm{C}$, assumindo pressão de fluidos de $5 \mathrm{kbar}$ (Metz et al 1968).

Os mármores do segmento Várzea do Capivarita caracterizam-se por uma paragênese mineral bastante diversificada, sendo divididos em mármores puros e mármores impuros. A paragênese $M$ em equilíbrio nos mármores puros está representada por $\mathrm{Cal}+\mathrm{Dol}$ $\pm \mathrm{Ol} \pm \mathrm{Phl}$, com textura granoblástica poligonal ou lobular, com granulação média a grossa e grãos subédricos a euédricos. Em temperaturas inferiores a $800^{\circ} \mathrm{C}$, a forsterita só pode ser produzida através da interação do mármore com fluidos externos ricos em $\mathrm{H}_{2} \mathrm{O}$ (Bucher \& Frey 1994). As reações formadoras da paragênese $\mathrm{M}_{1}$, equação (9) e (10) dependem da composição do fluido, podendo ocorrer em intervalo de temperatura a partir de $600^{\circ} \mathrm{C}\left(\mathrm{X}_{\mathrm{CO} 2}=\right.$ 0.1 , podendo atingir até $800^{\circ} \mathrm{C}\left(\mathrm{X}_{\mathrm{CO} 2}=1.0\right)$ (Spear 1993). A paragênese $\mathrm{Cal}+\mathrm{Dol}+\mathrm{Fo}$ persiste em rochas carbonáticas até condições de alto grau metamórfico (Spear 1993).

$$
\begin{gathered}
\mathrm{Dol}+\mathrm{Tr}=\mathrm{Cal}+\mathrm{FO}+\mathrm{H}_{2} \mathrm{O}+\mathrm{CO}_{2}(9) \\
\mathrm{Dol}+\mathrm{Di}=\mathrm{Cal}+\mathrm{Fo}+\mathrm{CO}_{2}(10)
\end{gathered}
$$

Os mármores impuros caracterizam-se por bandamento milimétrico, marcado pela alternância de bandas ricas em diopsídio, pargasita, tremolita, calcita e dolomita, e bandas ricas em olivina, flogopita, dolomita e calcita e bandas onde há predominância de carbonatos. A paragênese $\mathrm{M}_{1}$ em equilíbrio é composta por $\mathrm{Ol}+$ $\mathrm{Cal}+\mathrm{Phl}$ nas bandas de cor escura, em arranjos granoblásticos poligonais (Fig. 3h) e por $\mathrm{Di}+\mathrm{Cal}$ e nas bandas de cor clara. A formação da paragênese $\mathrm{Cal}+\mathrm{Fo}$, nos mármores impuros é similar à formação da mesma paragênese nos mármores puros. A primeira ocorrência de diopsídio ocorre em temperaturas acima de $670^{\circ} \mathrm{C}$ (Bucher \& Frey 1994), e a paragênese Di + Cal é formada pela reação (equação 11):

$$
\mathrm{Dol}+\mathrm{Tr}=\mathrm{Di}+\mathrm{Cal}(11)
$$

A paragênese retrogressiva hidratada nos mármores impuros é formada por intercrescimentos de $\mathrm{Tr}+$ Dol substituindo calcita + olivina, formados pela reação retrogressiva de hidratação, equação (12) (Schenk 1984):

$$
\mathrm{Fo}+\mathrm{Cal}+\mathrm{CO}_{2}+\mathrm{H}_{2} \mathrm{O}=\mathrm{Tr}+\mathrm{Dol}(12)
$$

Essa reação ocorre em intervalo de $600-650^{\circ} \mathrm{C}$ e em baixas pressões de $\mathrm{X}_{\mathrm{CO} 2}\left(0.1-0.5 \mathrm{X}_{\mathrm{CO} 2}\right)$ (Metz 1976, Kas \& Metz 1980, Eggert \& Kerrick 1980).

Química Mineral As análises foram obtidas com a microssonda eletrônica Cameca Camebax-Microbeam SX-50 do Laboratório do CPGq da Universidade Federal do Rio Grande do Sul (UFRGS), que apresenta limite de detecção (LD) $>1000$ ppm $(0,1 \%)$. As condições operacionais utilizadas para os diferentes minerais encontram-se na Tabela2. As análises realizadas (Tabela 3), visam o estudo das variações composicionais existentes entre mesmas fases minerais, e identificar evidências de desequilíbrio químico.

GNAISSES PELÍTICOS Nos gnaisses pelíticos (5 amostras) foram analisados $\mathrm{Grt}, \mathrm{Bt}, \mathrm{Kf}, \mathrm{Pl}$, Crd, Sil e Sp (Tabela 3a). A Grt, é solução sólida entre os membros-finais almandina (71-76\%), piropo $(11,4-15,4 \%)$, grossulária $(2,7-7,67 \%)$ e espessartina $(6,2-8,43 \%)$, sendo a almandina o componente dominante. Os teores de uvarovita e andradita exibem concentrações muito pequenas.

Foi verificado zoneamento químico, com aumento dos componentes Spss $(6,4$ a 8,4\%) e diminuição dos componentes Grs (2,5$6,0 \%)$ em direção às bordas. As concentrações de Alm (71 a 76\%) e Py (11 a 15\%) apresentam comportamentos variáveis. As variações composicionais desses componentes apresentam padrões irregulares de distribuição em toda extensão do cristal, indicando desequilíbrio químico.

As Grt ${ }_{2}$ apresentam composições distintas, determinadas pela composição da banda onde ocorrem. Nas bandas ricas em $\mathrm{Mg}$, os teores de Alm variam entre 69,4 e $75 \%$, Py entre 10 e $17,13 \%$, Grs entre 2,6 e 6,44\% e Spss entre 7,84 e 13,47\%. Nas bandas ricas em $\mathrm{Fe}$ a concentração de almandina varia entre 80,6 e $82,8 \%$, a de piropo entre 10,5 e $13,5 \%$, a de grossulária entre 2,6 e $3,0 \%$ e de espessartina entre 3,0 e $3,6 \%$.

Além da composição química distinta, Grt ${ }_{2}$ mostra padrões de zoneamento químico. Nas bandas ricas em $\mathrm{Mg}$, o zoneamento é caracterizado por enriquecimento das concentrações de Spss e Alm e empobrecimento de Grs e Py em direção às bordas do mineral. O desenvolvimento desse tipo de zoneamento químico em rochas de alto grau é atribuído à atuação de dois mecanismos em conjunto: (1) transferência de rede, onde fases são consumidas e formadas, afetando o equilíbrio em grandes extensões do grão (Spear 1993) e (2) troca catiônica, dirigida por difusão de troca de $\mathrm{Fe}-\mathrm{Mg}$, mecanismo que não afeta as proporções modais entre as fases envolvidas (Spear 1993). A ocorrência do mecanismo de troca de rede indica a entrada de água no sistema durante o resfriamento da rocha (Spear 1993).

As bandas ricas em Fe mostram variação da concentração de Py e Alm restritas às bordas de granada em contato com biotita, indicando que o mecanismo dominante foi o de troca catiônica. Esse mecanismo de troca não necessita influxo de água durante a trajetória retrogressiva da rocha, indicando que a entrada da mesma no sistema restringe-se a alguns segmentos do gnaisse pelítico.

$\mathrm{A} \mathrm{Grt}_{3}$ apresenta teores de Alm entre 79,8 e 84\%, de Py entre 9,2 e $13,7 \%$ de Grs entre 2,51 e 2,9 e de Spss entre 2,6 e 4,5\%. Ocorre 
Tabela 2 - Condições operacionais microssonda eletrônica.

\begin{tabular}{|l|c|c|c|}
\hline MINERAL & VOLTAGEM & AMPERAGEM & $\begin{array}{c}\text { DIÂMETRO } \\
\text { DO FEIXE }\end{array}$ \\
\hline Feldspatos & $15 \mathrm{KeV}$ & $10 \mathrm{nA}$ & $\phi=1 \mu \mathrm{m}$ \\
\hline Micas & $15 \mathrm{KeV}$ & $10 \mathrm{nA}$ & $\phi=1 \mu \mathrm{m}$ \\
\hline Granada & $15 \mathrm{KeV}$ & $25 \mathrm{nA}$ & $\phi=1 \mu \mathrm{m}$ \\
\hline Cordierita & $15 \mathrm{KeV}$ & $10 \mathrm{nA}$ & $\phi=1 \mu \mathrm{m}$ \\
\hline Carbonatos & $15 \mathrm{KeV}$ & $8 \mathrm{nA}$ & $\phi=5 \mu \mathrm{m}$ \\
\hline Piroxênios & $15 \mathrm{KeV}$ & $10 \mathrm{nA}$ & $\phi=5 \mu \mathrm{m}$ \\
\hline Olivina & $15 \mathrm{KeV}$ & $25 \mathrm{nA}$ & $\phi=5 \mu \mathrm{m}$ \\
\hline Escapolita & $15 \mathrm{KeV}$ & $10 \mathrm{nA}$ & $\phi=1 \mu \mathrm{m}$ \\
\hline
\end{tabular}

discreto aumento no teor de Alm e diminuição no componente Py nas bordas dos grãos analisados. Este zoneamento é localizado, restringindo-se espacialmente às porções de borda da granada em contato com a biotita (mecanismo de troca catiônica).

A composição da biotita é condicionada pela composição da banda onde ela ocorre. $\mathrm{A} \mathrm{Bt}_{1}$ em contato com $\mathrm{Grt}_{2}$ apresenta valores de $\mathrm{Al}^{\mathrm{vi}}$ entre 0,66 e 0,72 , de $\mathrm{Ti}^{\mathrm{vi}}$ entre 0,37 e 0,41 e razão $\mathrm{Mg}$ / $(\mathrm{Mg}+\mathrm{Fe})$ entre 0,40 e 0,41 . A Bt isolada por matriz quartzofeldspática apresenta valores de $A l^{v i}$ inferiores a $0,7(0,61$ e 0,69$)$, de $T i^{\text {vi }}$ entre 0,37 e 0,49 e razão $\mathrm{Mg} /(\mathrm{Mg}+\mathrm{Fe})$ entre 0,43 e 0,44. Observa-se diminuição da razão $\mathrm{Mg} /(\mathrm{Mg}+\mathrm{Fe})$, indicando enriquecimento em Fe na biotita em contato com porfiroblastos $\mathrm{Grt}_{2}$. Essa diminuição é compatível com biotita afetada por reações de troca de rede (Spear 1993). Os grãos isolados na matriz quartzofeldspática não apresentam diminuição dessa razão, indicando que não foram afetadas por esse processo.

$\mathrm{ABt}_{2}$ ocorre em equilíbrio com $\mathrm{Grt}_{2}$ e Grt $\mathrm{ABt}_{3}$ em contato com $\mathrm{Grt}_{2}$ apresenta valores de $\mathrm{Al}{ }^{\mathrm{vi}}$ entre $0,6 \mathrm{e} 0,7$, de Tivi entre $0,35 \mathrm{e} \mathrm{0,49}$ e razão $\mathrm{Mg} /(\mathrm{Mg}+\mathrm{Fe})$ entre 0,38 e 0,41 . $\mathrm{A} \mathrm{Bt}$, na matriz quartzo feldspática apresenta valores de $\mathrm{Al}^{\mathrm{vi}}$ entre 0,6 e 0,7 , de $\mathrm{Ti}^{\mathrm{vi}}$ entre 0,42 e 0,5 e razão $\mathrm{Mg} /(\mathrm{Mg}+\mathrm{Fe})$ entre 0,34 e 0,36. O enriquecimento em $\mathrm{Mg}$ observado na $\mathrm{Bt}_{2}$ em contato com $\mathrm{Grt}_{2} \mathrm{e} \mathrm{Grt}_{3} \mathrm{em}$ relação à $\mathrm{Bt}_{2}$ isolada na matriz quartzo -feldspática é comum em biotita afetada por processos de troca catiônica (Spear 1993).

$\mathrm{A} \mathrm{Bt}_{3}$ ocorre apenas em amostras onde $\mathrm{Grt}_{1}$ e Grt mostram padrões de zoneamento compatíveis com mecanismo de transferência de rede, indicando que essa biotita é produto da reação que gera o zoneamento da $\mathrm{Grt}_{1}$ e $\mathrm{Grt}_{2}$, equação (13). $\mathrm{A} \mathrm{Bt}_{3}$ apresenta valores de $\mathrm{Al}^{\text {vi }}$ em torno de $0,7 \mathrm{e} 0,75$, de Ti ${ }^{\text {vi }}$ entre 0,35 e 0,38 e razão $\mathrm{Mg} /(\mathrm{Mg}+\mathrm{Fe})$ de 0,42 .

$$
\mathrm{Grt}+\mathrm{Kf}+\mathrm{H}_{2} \mathrm{O}=\mathrm{Sil}+\mathrm{Bt}+\mathrm{Qtz}(13)
$$

Os conteúdos de $\mathrm{Al}^{\mathrm{vi}}$ e de $\mathrm{Ti}^{\mathrm{vi}}$ encontrado em $\mathrm{Bt}_{\text {, }}$ e $\mathrm{Bt}_{2}$ são compatíveis com biotita do fácies granulito (Guidotti 1984). $\mathrm{Em} \mathrm{Bt}_{3}$ o conteúdo de $\mathrm{Al}^{\mathrm{vi}}$ é típico de pelitos de fácies anfibolito superior (Guidotti 1984), indicando que $\mathrm{Bt}_{1} \mathrm{e} \mathrm{Bt}_{2}$ foram geradas por reações durante o metamorfismo de alto grau, enquanto que $\mathrm{Bt}_{3}$ é produto de reações de temperatura mais baixa, durante o resfriamento da rocha com influxo de $\mathrm{H}_{2} \mathrm{O}$.

O plagioclásio apresenta teores de anortita (An) entre 41,25\% e $35 \%$, o que o classifica como andesina. A concentração de potássio no plagioclásio é baixa, variando entre $0 \%$ e $2 \%$. Os grãos analisados não apresentam zoneamento.

O feldspato potássico apresenta pequena variação composicional, $\mathrm{Or}_{89}$ a $\mathrm{Or}_{97}$ e $\mathrm{An}_{0}$ a $\mathrm{An}_{2,6}$. Em algumas análises foram reconhecidas pertitas do tipo interlocking e interpenetração (Deer et al. 1992), onde se verificou teor de $\mathrm{An}_{0.9}$ e $\mathrm{Or}_{95}$, indicando reequilíbrio composicional após as condições de pico térmico.
$\mathrm{Na}$ cordierita a proporção de $\mathrm{Fe}^{2+}$ para $\mathrm{Mg}^{2+}$ é de aproximadamente $1: 1$, com razão $100 \mathrm{Mg} /(\mathrm{Mg}+\mathrm{Fe})$ em torno de 50 , indicando uma variedade rica em $\mathrm{Fe}$. Não foram observados zoneamentos composicionais ou variações químicas significativas entre grãos de cordierita com diferentes relações texturais. Ocorrem pequenas proporções de álcalis, o que sugere a ausência de fases gasosas coexistindo com feldspatos (Schereyer 1965). As pequenas concentrações de $\mathrm{H}_{2} \mathrm{O}$ observadas indicam que essas cordieritas são de alta temperatura (Lepezin \& Melenevsky 1977).

Os grãos de espinélio apresentam $90 \%$ de componente hercinita e $10 \%$ de espinélio, que corresponde à composição típica da hercinita em equilíbrio com silimanita (Holdaway 1976).

A silimanita ocorre de forma restrita e não foram observadas variações significativas, apresentando composições relativamente puras, com pequenos percentuais de $\mathrm{Fe}^{2+}(0.013-0.017)$ e de $\mathrm{K}$ $(0,000-0,0008)$ cátions p.u.f.

GNAISSE MÁFICO Nos gnaisses máficos foram analisados Cpx, Opx e Pl (Tabela 3b). Os grãos de ortopiroxênios consistem de soluções sólidas de En (62\%-65\%) - Fs (32\%-36\%). Foi identificado zoneamento composicional mínimo de $\mathrm{Fe}-\mathrm{Mg}$ em pontos em contato com biotita, com aumento de 1 a $2 \%$ nas concentrações de Fs e diminuição de En. Esse zoneamento indica reequilíbrio por reações de troca durante o resfriamento. Além do zoneamento, a ocorrência de lamelas de Di também indica exsolução durante o resfriamento. Dessa forma, as composições obtidas provavelmente não refletem as composições iniciais dos cristais.

Os grãos de clinopiroxênio são soluções sólidas de diopsídio - hedenbergita, ricos em $\mathrm{Mg}\left(\mathrm{X}_{\mathrm{Mg}}=0,77-0,80\right)$. Os conteúdos de $\mathrm{Mn}(1,1-1,6 \%)$ e $\mathrm{Al}(1,1-2,6 \%)$ ocorrem em pequenas concentrações. Foram observadas pequenas diminuições da razão $\mathrm{Mg} /$ $(\mathrm{Mg}+\mathrm{Fe})$ nos pontos analisados nas bordas dos $\mathrm{Cpx}$ em contato com Bt.

O plagioclásio apresenta teores de $\mathrm{An}$ entre $\mathrm{An}_{70}$ e $\mathrm{An}_{82}$, que os classifica como bywtonita. A concentração de potássio no Pl é baixa, variando de $\mathrm{Or}_{0,1}$ a $\mathrm{Or}_{0,8}$. Foram observadas variações composicionais em cristais em contato com os piroxênios alterados, onde ocorre diminuição dos teores de $\mathrm{An}\left(\mathrm{An}_{68}\right)$. Teores mais elevados de $\mathrm{An}\left(\mathrm{An}_{80}\right)$ foram encontrados em inclusões de $\mathrm{Pl} \mathrm{em}$ $\mathrm{Px}$, bem como em grãos da matriz quartzo-feldspática.

GNAISSE CALCIOSSILICÁTICO Os grãos de clinopiroxênio dos gnaisses calciossilicatados são soluções sólidas de diopsídio - hedenbergita, com composições variáveis (Tabela 3b). Nas bandas de gnaisse intercaladas aos gnaisses pelíticos, o clinopiroxênio é rico em $\mathrm{Mg}\left(\mathrm{X}_{\mathrm{Mg}}=0,74-0,75\right)$, com pequenas concentrações de $\mathrm{Mn}(<1,8 \%)$ e Al (1-1,6\%). No segmento Arroio Canhão, o clinopiroxênio é mais rico em $\mathrm{Fe}\left(\mathrm{X}_{\mathrm{Mg}}=0,42-0,48\right)$ com Al variando entre $(1,7-3,2 \%)$ e baixas concentrações de $\mathrm{Mn}(<1 \%)$. Foram identificadas discretas variações composicionais de $\mathrm{Cpx}$ em contato com Grs, onde ocorre diminuição da razão $\mathrm{Fe} /(\mathrm{Fe}+\mathrm{Mg})$ de 0,57 para 0,49 e 0,50 .

O plagioclásio apresenta $\mathrm{An}$ entre $\mathrm{An}_{82}$ e $\mathrm{An}_{89}$, classificandoo como bytownita. A concentração de potássio no Pl é inferior a $1 \%$. Ocorre pequena diminuição do teor de An nos contatos de $\mathrm{Pl}$

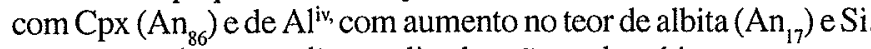

Os grãos de escapolita analisados são carbonáticos e apresentam composição homogênea. As porcentagens calculadas do componente meionita (Shaw 1960) variam entre $79,2 \%$ e $82 \%$, e as porcentagens do equivalente anortita (EqAn) entre $68 \%$ e $71 \%$. As composições observadas são típicas de rochas carbonáticas 
Tabela 3 - Dados representativos de Química Mineral da SMVC.

\begin{tabular}{|c|c|c|c|c|c|c|c|c|c|c|c|}
\hline \multicolumn{12}{|c|}{ GNAISSE PELITICO } \\
\hline mineral & Grt $_{1}$ & Grt $_{2}$ & Grt $_{2}$ & $\mathrm{Grt}_{3}$ & $\mathbf{B t}_{1}$ & $\mathbf{B t}_{2}$ & $\mathrm{Bt}_{3}$ & Crd & Spl & $\mathbf{K f}$ & PI \\
\hline$n^{\circ}$ ponto & GRD11 & GRD20 & GRD9 & GRD17 & P8 & PB12 & P12 & PC10 & PS2 & PA6 & PG1A \\
\hline $\mathrm{SiO}_{2}$ & 37.35 & 37.25 & 37.27 & 37.49 & 34.91 & 33.45 & 35.34 & 48.21 & 0.02 & 66.18 & 62.24 \\
\hline $\mathrm{TiO}_{2}$ & 0.00 & 0.03 & 0.04 & 0.03 & 3.60 & 3.88 & 3.13 & 0.00 & 0.00 & 0.00 & 0.00 \\
\hline $\mathrm{Al}_{2} \mathrm{O}_{3}$ & 21.12 & 21.27 & 21.29 & 21.51 & 18.13 & 18.54 & 18.64 & 33.17 & 58.30 & 18.63 & 24.93 \\
\hline $\mathrm{Cr}_{2} \mathrm{O}_{3}$ & 0.03 & 0.02 & 0.01 & 0.06 & 0.02 & 0.02 & 0.09 & 0.00 & 0.00 & 0.00 & 0.00 \\
\hline $\mathrm{Fe}_{2} \mathrm{O}_{3}$ & 0.18 & 0.00 & 0.00 & 0.00 & 0.00 & 0.00 & 0.00 & 0.00 & 0.00 & 0.00 & 0.00 \\
\hline $\mathrm{FeO}$ & 33.33 & 32.71 & 36.41 & 36.37 & 20.41 & 22.50 & 20.41 & 10.69 & 36.25 & 0.06 & 0.02 \\
\hline $\mathrm{MnO}$ & 2.88 & 3.56 & 1.49 & 1.62 & 0.27 & 0.04 & 0.22 & 0.00 & 0.00 & 0.00 & 0.00 \\
\hline MgO & 3.35 & 4.10 & 3.01 & 3.27 & 8.76 & 7.33 & 8.50 & 6.58 & 2.45 & 0.00 & 0.00 \\
\hline $\mathrm{CaO}$ & 2.32 & 1.19 & 1.01 & 1.07 & 0.00 & 0.09 & 0.02 & 0.00 & 0.00 & 0.06 & 6.21 \\
\hline $\mathrm{Na}_{2} \mathrm{O}$ & 0.00 & 0.00 & 0.00 & 0.00 & 0.00 & 0.11 & 0.07 & 0.00 & 0.00 & 1.53 & 6.71 \\
\hline $\mathrm{K}_{2} \mathrm{O}$ & 0.00 & 0.00 & 0.00 & 0.00 & 9.87 & 8.62 & 9.51 & 0.00 & 0.00 & 14.81 & 0.25 \\
\hline Total & 100.58 & 100.19 & 100.53 & 101.42 & 99.91 & 98.45 & 99.94 & 98.65 & 97.00 & 101.25 & 100.36 \\
\hline O p.u.f. & 12 & 12 & 12 & 12 & 22 & 22 & 22 & 18 & 32 & 8 & 8 \\
\hline $\mathrm{Si}$ & 5.973 & 5.957 & 5.982 & 5.960 & 5.352 & 5.220 & 5.401 & 4.993 & 0.000 & 3.003 & 2.660 \\
\hline $\mathrm{Ti}$ & 0.000 & 0.003 & 0.005 & 0.003 & 0.415 & 0.456 & 0.359 & 0.000 & 0.000 & 0.000 & 0.000 \\
\hline Al vi & - & - & $=$ & -- & 0.628 & 0.629 & 0.758 & 3.041 & 16.043 & 0.996 & 1.347 \\
\hline Aliv & 3.980 & 4.023 & 4.027 & 4.030 & 2.648 & 2.780 & 2.599 & 1.007 & 0.000 & 0.000 & 0.000 \\
\hline $\mathrm{Cr}$ & 0.040 & 0.002 & 0.001 & 0.007 & 0.002 & 0.002 & 0.011 & 0.000 & 0.000 & 0.000 & 0.000 \\
\hline $\mathrm{Fe}+2$ & 4.450 & 4.376 & 4.880 & 4.837 & 2.617 & 2.936 & 2.608 & 0.925 & 7.078 & 0.002 & 0.001 \\
\hline Mn & 0.390 & 0.483 & 0.203 & 0.219 & 0.035 & 0.006 & 0.028 & 0.000 & 0.000 & 0.000 & 0.000 \\
\hline $\mathrm{Zn}$ & 0.000 & 0.000 & 0.000 & 0.000 & 0.000 & 0.000 & 0.000 & 0.000 & 0.000 & 0.000 & 0.000 \\
\hline $\mathrm{Mg}$ & 0.799 & 0.978 & 0.720 & 0.777 & 2.002 & 1.706 & 1.936 & 1.016 & 0.851 & 0.000 & 0.000 \\
\hline $\mathrm{Ca}$ & 0.399 & 0.203 & 0.174 & 0.181 & 0.000 & 0.014 & 0.003 & 0.000 & 0.000 & 0.003 & 0.371 \\
\hline $\mathrm{Na}$ & 0.000 & 0.000 & 0.000 & 0.000 & 0.000 & 0.033 & 0.020 & 0.000 & 0.000 & 0.134 & 0.562 \\
\hline $\mathbf{K}$ & 0.000 & 0.000 & 0.000 & 0.000 & 1.930 & 1.717 & 1.854 & 0.000 & 0.000 & 0.857 & 0.015 \\
\hline soma & 16.024 & 16.026 & 15.999 & 16.014 & 15.629 & 15.499 & 15.580 & 15.032 & 23.975 & 4.995 & 4.955 \\
\hline
\end{tabular}

\begin{tabular}{|c|c|c|c|c|c|c|c|c|c|c|c|c|c|c|}
\hline \multicolumn{6}{|c|}{ Mármores Impuros - VC 15-09 } & \multicolumn{4}{|c|}{ Gn. Máfico - VC 02-18 } & \multicolumn{5}{|c|}{ Gn. Calciossilicatado - VC 15-09 } \\
\hline $\min$ & Cal & $\mathrm{Tr}$ & $\mathbf{P h}$ & Parg & $\mathrm{Cpx}$ & Opx & Opx & Cpx & PI & Grs-1 & Grs-2 & Cpx & Scp & Scp \\
\hline$n^{\circ}$ ponto & cal4 & pp2 & bt12 & pp3A & pp7 & pp8 & pp10 & op21 & pg3 & grd1 & grd7 & px6 & pm6 & pm6 \\
\hline $\mathrm{SiO}_{2}$ & 0.000 & 57.00 & 43.14 & 48.31 & 56.93 & 56.43 & 55.99 & 55.18 & 48.94 & 40.42 & 39.88 & 52.33 & 46.18 & 46.178 \\
\hline $\mathrm{TiO}_{2}$ & 0.000 & 0.207 & 0.267 & 0.000 & 0.013 & 0.069 & 0.095 & 0.074 & 0.000 & 0.000 & 0.777 & 0.000 & 0.000 & 0.000 \\
\hline $\mathrm{Al}_{2} \mathrm{O}_{3}$ & 0.000 & 2.419 & 14.44 & 12.46 & 0.244 & 0.232 & 0.307 & 0.528 & 33.64 & 21.22 & 18.94 & 0.697 & 28.84 & 28.842 \\
\hline $\mathrm{Cr}_{2} \mathrm{O}_{3}$ & 0.000 & 0.000 & 0.000 & 0.000 & 0.000 & 0.004 & 0.011 & 0.000 & 0.000 & 0.021 & 0.026 & 0.000 & 0.000 & 0.000 \\
\hline $\mathrm{Fe}_{2} \mathrm{O}_{3}$ & 0.000 & 0.000 & 0.000 & 0.000 & 0.000 & 0.000 & 0.000 & 0.000 & 0.000 & 2.573 & 4.959 & 0.000 & 0.000 & 0.000 \\
\hline $\mathrm{FeO}$ & 0.177 & 0.000 & 0.391 & 0.663 & 0.385 & 19.14 & 18.85 & 6.868 & 0.030 & 0.949 & 0.612 & 17.24 & 0.010 & 0.016 \\
\hline $\mathrm{MnO}$ & 0.000 & 0.304 & 0.000 & 0.000 & 0.000 & 1.068 & 1.065 & 0.415 & 0.000 & 0.164 & 0.134 & 0.198 & 0.000 & 0.000 \\
\hline $\mathrm{MgO}$ & 4.524 & 0.000 & 28.10 & 20.68 & 18.30 & 20.40 & 20.38 & 14.98 & 0.000 & 0.064 & 0.017 & 7.102 & 0.000 & 0.005 \\
\hline CaO & 95.28 & 24.44 & 0.000 & 12.94 & 26.26 & 1.005 & 1.152 & 23.20 & 16.63 & 36.80 & 36.83 & 24.04 & 19.15 & 19.152 \\
\hline $\mathrm{Na}_{2} \mathrm{O}$ & 0.000 & 13.54 & 0.827 & 2.368 & 0.027 & 0.000 & 0.000 & 0.083 & 2.099 & 0.000 & 0.000 & 0.054 & 2.291 & 2.291 \\
\hline $\mathrm{K}_{2} \mathrm{O}$ & 0.000 & 1.098 & 9.329 & 0.461 & 0.000 & 0.000 & 0.000 & 0.000 & 0.074 & 0.000 & 0.000 & 0.000 & 0.366 & 0.366 \\
\hline Total & 99.99 & 99.01 & 100.9 & 98.35 & 102.3 & 98.35 & 97.84 & 101.3 & 101.4 & 102.2 & 102.2 & 101.7 & 96.85 & 96.852 \\
\hline Op.u.f. & $\cdot$ & 23 & 22 & 23 & 6 & 6 & 6 & 6 & 8 & 24 & 12 & 6 & 25 & 25 \\
\hline $\mathrm{Si}$ & 0.000 & 7.767 & 5.9470 & 6.655 & 2.006 & 2.093 & 2.087 & 2.009 & 2.208 & 5.998 & 5.976 & 2.002 & 6.940 & 6.940 \\
\hline $\mathrm{Ti}$ & 0.000 & 0.000 & 0.0280 & 0.000 & 0.003 & 0.002 & 0.003 & 0.044 & 0.000 & 0.000 & 0.088 & 0.000 & 0.000 & 0.000 \\
\hline Al vi & 0.000 & 0.220 & 2.0530 & 0.677 & 0.000 & 0.010 & 0.014 & 0.028 & 1.789 & - & & 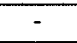 & & \\
\hline Aliv & 0.000 & 0.233 & 0.2940 & 1.345 & 0.010 & 0.000 & 0.000 & 0.000 & 0.000 & 3.711 & 3.346 & 0.031 & 5.109 & 5.109 \\
\hline $\mathrm{Cr}$ & 0.000 & 0.000 & 0.0000 & 0.000 & 0.000 & 0.594 & 0.588 & 0.209 & 0.001 & 0.003 & 0.003 & 0.000 & 0.000 & 0.000 \\
\hline $\mathrm{Fe}+2$ & 0.003 & 0.000 & 0.0450 & 0.076 & 0.011 & 0.034 & 0.034 & 0.013 & 0.000 & 0.118 & 0.077 & 0.551 & 0.002 & 0.002 \\
\hline $\mathrm{Mn}$ & 0.000 & 0.000 & 0.0000 & 0.000 & 0.000 & 1.128 & 1.132 & 0.813 & 0.000 & 0.021 & 0.017 & 0.006 & 0.000 & 0.000 \\
\hline $\mathrm{Fe}+3$ & 0.000 & 0.000 & 0.0000 & 0.000 & 0.000 & 0.000 & 0.000 & 0.000 & 0.000 & 0.287 & 0.559 & 0.000 & 0.000 & 0.000 \\
\hline $\mathrm{Mg}$ & 0.112 & 4.743 & 5.7750 & 4.247 & 0.954 & 0.040 & 0.046 & 0.905 & 0.804 & 0.014 & 0.004 & 0.405 & 0.001 & 0.001 \\
\hline Ca & 1.699 & 1.939 & 0.0000 & 1.911 & 0.985 & 0.000 & 0.000 & 0.006 & 0.184 & 5.851 & 5.914 & 0.985 & 3.084 & 3.084 \\
\hline $\mathrm{Na}$ & 0.000 & 0.277 & 0.2210 & 0.758 & 0.004 & 0.000 & 0.000 & 0.000 & 0.004 & 0.000 & 0.000 & 0.004 & 0.668 & 0.668 \\
\hline $\mathbf{K}$ & 0.000 & 0.000 & 1.6410 & 0.081 & 0.000 & 0.000 & 0.000 & 0.000 & 4.991 & 0.000 & 0.000 & 0.000 & 0.070 & 0.070 \\
\hline soma & 1.814 & 23.108 & 16.0040 & 22.997 & 3.981 & 3.9 & 3.903 & 3.98 & 4.991 & 16.001 & 15.983 & 4.016 & 15.874 & 15.874 \\
\hline
\end{tabular}


de alto grau (Graziani \& Lucchese 1982).

A zoisita ocorre em raras amostras. O sítio octaédrico (1) é ocupado em $99,92 \%$ por $\mathrm{Ca}$, com pequenas quantidades de $\mathrm{Mg}$ $(0,0782 \%)$ e o sítio octaédrico (2) apresenta $95,33 \%$ de Al, com $4,665 \mathrm{de} \mathrm{Fe}^{+3}$. O sítio tetraédrico é preenchido exclusivamente por $\mathrm{Si}$ (3,16 cátions por unidade de fórmula).

Os cristais de granada são soluções sólidas de grossuláriaandradita, com pequenas concentrações de outros elementos e apresentam variações composicionais de acordo com suas relações texturais. Os grãos de Grt poiquiloblásticos apresentam componente Grs entre $85 \%$ e $94 \%$ e Andr entre $4 \%$ e $10 \%$. As coroas de grossulária que envolvem Scp apresentam menores concentrações de Grs (82\%) e maiores de Andr (15\%).

MÁRMORES Os carbonatos dos mármores puros são representados por calcita e dolomita (Tabela $3 \mathrm{~b}$ ). Os cristais analisados de calcita são virtualmente $\mathrm{CaCO}_{3}$ puro, com algumas amostras apresentando pequenas quantidades de $\mathrm{Mg}(0,08-0,10)$. A dolomita apresenta quantidades apreciáveis de $\mathrm{Mg}(0,95-0,98$ a.p.u.f). Além disso, invariavelmente mostra pequenos excessos de Ca sobre $\mathrm{Mg}+\mathrm{Fe}+\mathrm{Mn}$ (Droop \& Al-Filali 1996).

Nos mármores impuros a calcita analisada apresenta pequenas quantidades de $\mathrm{SiO}_{2}(0-0,7 \%), \mathrm{Al}_{2} \mathrm{O}_{3}(0-0,03 \%)$ e $\mathrm{FeO}(0-0,16 \%)$, com quantidades apreciáveis de $\mathrm{MgO}(1,8-6,5 \%)$. Já os piroxênios pertencem à série diopsídio - hedenbergita, com diopsídio variando entre 94 e $96 \%$ e hedenbergita em torno de $1 \%$. Não foram identificadas variações composicionais ou zoneamento químico no interior dos cristais ou nos contatos dos grãos com outros minerais. Por sua vez, os anfibólios são cálcicos (Leake 1978), e podem ser classificados como tremolita e pargasita.

Os cristais de biotita possuem composição dominada pelo membro final flogopita. Não ocorrem variações significativas da razão $\mathrm{Mg} / \mathrm{Mg}+\mathrm{Fe}$, com valores entre $0,9904 \mathrm{e} 0,9934$ na flogopita de alta temperatura dos mármores impuros e 0,9896 na flogopita dos mármores puros. Com relação às concentrações de $\mathrm{Al}^{\mathrm{VI}}$, a flogopita dos mármores impuros apresenta teores entre 0,27 e 0,38.

Interpretação dos Dados de Química Mineral A interpretação dos dados de química mineral, visando a investigação do equilíbrio/desequilíbrio químico é essencial para o estabelecimento de parâmetros para a seleção das amostras a serem utilizadas nos cálculos termobarométricos. Na maioria das rochas investigadas as fases minerais apresentam homogeneidade composicional, indicando que o equilibrio químico foi atingido. As evidências de desequilíbrio, principalmente o zoneamento químico, são localizadas e observadas em fases ferro-magnesianas em contato com outros minerais ferro-magnesianos. Esse tipo de desequilíbrio é comum em rochas de alto grau, sendo atribuído à difusão de Fe$\mathrm{Mg}$ entre fases em contato durante o resfriamento após as condições de pico (Spear \& Florence 1992).

Nas amostras de gnaisse pelítico, diferentes padrões de zoneamento foram identificados. A granada $\mathrm{Grt}_{1}$, assim como a granada $\mathrm{Grt}_{2}$ nas bandas ricas em $\mathrm{Mg}$, apresenta zoneamento compatível com mecanismos de transferência de rede associado a reações retrogressivas, descritos por Spear \& Florence (1992), e não foram utilizadas na geotermobarometria, já que esse processo afeta grandes extensões do grão e fornece temperaturas superiores àquelas atingidas no pico térmico. $\mathrm{A}$ biotita $\mathrm{Bt}_{1}$, quando em contato com granada Grt também apresenta composições compatíveis com biotita afetada pelas mesmas reações de troca de rede, mas quando esta se encontra isolada na matriz quartzo- feldspática não ocorre diminuição da razão $\mathrm{Mg} /(\mathrm{Mg}+\mathrm{Fe})$, indicando que esses grãos isolados não foram afetados por esse processo.

A granada $\mathrm{Grt}_{2}$ nas bandas ricas em Fe e a granada $\mathrm{Grt}_{3}$ exibem padrões de zoneamento compatíveis com aqueles gerados por reações de troca catiônica. A biotita em contato com essa granada apresenta aumento da razão $\mathrm{Mg} /(\mathrm{Mg}+\mathrm{Fe})$, em relação à biotita da mesma amostra que se encontrava isolada pela matriz quartzofeldspática, típico de mecanismos de troca catiônica.

Desse modo, os cristais de biotita selecionados para serem utilizados na obtenção de dados termobarométricos foram aqueles isolados na matriz quartzo-feldspática, em amostras com granada apresentando zoneamento gerado apenas por troca catiônica, preservando as composições do pico térmico (Spear 1991). Os porfiroblastos de granada selecionados para a geotermobarometria foram os que apresentaram maior dimensão e padrão de zoneamento típico de troca catiônica, sendo utilizadas as composições de núcleo (Spear 1991).

Resultados Geotermobarométricos Foram obtidos valores de pressão e temperatura para um total de 5 amostras da Suíte Metamórfica Várzea do Capivarita. O maior número de resultados termométricos foi obtido para o gnaisse pelítico, que possui paragêneses minerais mais apropriadas para este fim. Nessas rochas as reações utilizadas nos cálculos de temperatura (Tabela 4) correspondem aos termômetros granada-biotita, granadacordierita, biotita-cordierita e espinélio-cordierita.

Os dados termobarométricos foram obtidos com a utilização do programa THERMOCALC V.3.01 (Holland \& Powell 1998), com atualização dos dados termodinâmicos de Holland e Powell (2001). Esse programa calcula as condições de equilíbrio para cada reação possível, utilizando as atividades dos membros finais das paragêneses em equilíbrio, tendo por base a equação geral do equilíbrio. A abordagem combina todas as informações de um conjunto independente de reações, selecionando as reações em equilíbrio na tentativa de determinar as condições de PT da rocha. O programa ainda determina erros derivados de incertezas dos cálculos termodinâmicos, sistemáticos (incertezas nos dados termodinâmicos e modelos de atividade) e aleatórios (incertezas analíticas). As atividades dos membros finais foram obtidas com o programa AX (Holland 1998), que fornece atividades para a utilização de cálculos termobarométricos.

No gnaisse pelítico o geotermômetro granada-biotita, um dos termômetros com maior número de calibrações conhecidas em dados experimentais (e.g. Ferry \& Spear 1978, Ganguly \& Saxena 1984 ), forneceu temperaturas variando entre $732 \mathrm{e} 755^{\circ} \mathrm{C}$ para as pressões estimadas com base nas paragêneses minerais ( 3 a 4 kbar), não havendo dispersão de resultados. Os erros calculados pelo THERMOCALC foram em torno de $130^{\circ} \mathrm{C}$. Os erros atribuídos a esse geotermômetro relacionam-se a fatores como carência de quantificação do $\mathrm{Fe}^{3+}$ na biotita, efeito de outros componentes além do $\mathrm{Fe}-\mathrm{Mg}$ (Ca-Mn na Grt, Ti-Cl na Bt) e trocas retrogressivas entre as fases, que modificam as razões $\mathrm{Fe} / \mathrm{Mg}$. Os resultados obtidos com esse método apresentam coerência com os valores de temperatura estimados com o estudo de petrologia metamórfica.

O geotermômetro granada-cordierita (e.g. Wood 1973, Currie 1974, Holdaway \& Lee 1977) forneceu temperaturas entre 700 e $747^{\circ} \mathrm{C}(\mathrm{P} 3-4 \mathrm{kbar})$, ligeiramente inferiores às do termômetro granada-biotita, o que pode ter sido ocasionado por diversos fatores. Dentre os problemas mais comuns estão à hidratação da cordierita, ou desequilíbrio químico, que afeta as propriedades 
termodinâmicas do mineral (Carpenter et al. 1983). Ainda assim, os erros calculados pelo programa THERMOCALC para as temperaturas obtidas permaneceram entre $89 \mathrm{e} 96^{\circ} \mathrm{C}$.

As temperaturas obtidas com o geotermômetro cordieritaespinélio (Berg 1977, Lal et al. 1978) foram as mais baixas, variando entre $661 \mathrm{e} 675^{\circ} \mathrm{C}$ (P entre 3-4Kbar), com erro calculado de $95^{\circ} \mathrm{C}$. Isso porque ocorre reequilíbrio de $\mathrm{Fe}-\mathrm{Mg}$ entre as duas fases durante o resfriamento, e este prossegue até temperaturas muito baixas (Kars et al. 1980).

Pela aplicação do método das abordagens múltiplas (Powell \&
Holland 1998), obteve-se pressões e temperaturas médias (Tabela 4). As condições médias de PT foram de $3.4 \pm 0.5 \mathrm{kbar}$ e $770 \pm 63^{\circ} \mathrm{C}$ (VC 17-03), 3.4 $\pm 0.5 \mathrm{kbar}$ e $756 \pm 61^{\circ} \mathrm{C}$ (VC 17-04) (Tabela 4). Os resultados são consistentes com os valores obtidos com o termômetro granada-biotita e granada-cordierita na paragênese 1 . As condições de PT médias fornecidas pela amostra VC 02-06 foram inferiores às temperaturas obtidas nas demais amostras, provavelmente porque as fases utilizadas nos experimentos foram atingidas pelos efeitos da retrogressão pós-pico metamórfico, com maior intensidade, como indicado pelos estudos de química mine-

Tabela 4 - Resultados termobarométricos dos segmentos Cerro Partido, Arroio Canhão e Várzea do Capivarita, obtidos com o programa THERMOCALC (Holland e Powell 1998).

\begin{tabular}{|c|c|c|c|c|c|c|c|c|c|c|}
\hline$N^{\circ} a m o s t r a$ & Assembléia & Reação & & & & & & & & \\
\hline \multicolumn{11}{|c|}{ SEGMENTO CERRO PARTIDO } \\
\hline \multirow{3}{*}{$\begin{array}{c}\text { Gnaisse } \\
\text { Pelítico } \\
\text { VC 02-06 } \\
\end{array}$} & \multirow{3}{*}{$\begin{array}{c}\text { Grd+crd+bio+pl+ } \\
\mathrm{qz}+\mathrm{Kf} \pm \mathrm{sp} \pm \text { sill }\end{array}$} & & P Kbar & 2 & 3 & 4 & 5 & 6 & sdT & sdP \\
\hline & & alm+ph $=p y+a n n$ & $\mathrm{~T}^{\circ} \mathrm{C}$ & 737 & 742 & 748 & 753 & 759 & 135 & 24 \\
\hline & & alm + Mgcrd $=$ py+Fecrd & $\mathrm{T}^{\circ} \mathrm{C}$ & 575 & 580 & 585 & 590 & 595 & 70 & 15 \\
\hline \multirow{4}{*}{$\begin{array}{c}\text { Gnaisse } \\
\text { Pelítico } \\
\text { VC 17-04 }\end{array}$} & \multirow{4}{*}{$\begin{array}{c}\text { Grd+crd+bio+pl+ } \\
\mathrm{qz}+\mathrm{Kf} \pm \mathrm{sp} \pm \text { sill }\end{array}$} & & P Kbar & 2 & 3 & 4 & 5 & 6 & sdT & $\mathrm{sdP}$ \\
\hline & & $\mathrm{alm}+\mathrm{ph}=\mathrm{py}+\mathrm{ann}$ & $\mathrm{T}^{\circ} \mathrm{C}$ & 726 & 732 & 737 & 743 & 748 & 137 & 25 \\
\hline & & alm $+\mathrm{Mgcrd}=\mathrm{py}+\mathrm{Fecrd}$ & $\mathrm{T}^{\circ} \mathrm{C}$ & 698 & 703 & 709 & 714 & 720 & 89 & 16 \\
\hline & & Mgcrd + hrc $=$ Fecrd $+s p$ & $\mathrm{~T}^{\circ} \mathrm{C}$ & 656 & 661 & 665 & 669 & 674 & 95 & 15 \\
\hline \multirow{4}{*}{$\begin{array}{c}\text { Gnaisse } \\
\text { Pelítico } \\
\text { VC 17-03 }\end{array}$} & \multirow{4}{*}{$\begin{array}{c}\text { Grd+crd+bio+pl+ } \\
\mathrm{qz}+\mathrm{Kf} \pm \mathrm{sp} \pm \text { sill }\end{array}$} & & P Kbar & 2 & 3 & 4 & 5 & 6 & sdT & sdP \\
\hline & & $\mathrm{alm}+\mathrm{ph}=\mathrm{py}+\mathrm{ann}$ & $\mathrm{T}^{\circ} \mathrm{C}$ & 744 & 749 & 755 & 761 & 766 & 142 & 26 \\
\hline & & alm + Mgcrd $=$ py+Fecrd & $\mathrm{T}^{\circ} \mathrm{C}$ & 735 & 741 & 747 & 752 & 758 & 96 & 16 \\
\hline & & Mgcrd + hrc $=$ Fecrd + sp & $\mathrm{T}^{\circ} \mathrm{C}$ & 667 & 670 & 675 & 679 & 684 & 99 & 22 \\
\hline \multicolumn{11}{|c|}{ THERMOCALC (Holland \& Powell 1998) - Método das Múltiplas Reaçōes } \\
\hline \multirow{7}{*}{$\begin{array}{c}\text { Gnaisse } \\
\text { Pelítico } \\
\text { vC 02-06 }\end{array}$} & & \multirow{3}{*}{ Temperatura média } & P fixa & 2.0 & 3.0 & 4.0 & 5.0 & 6.0 & \multirow{3}{*}{\multicolumn{2}{|c|}{$\begin{array}{c}7.0 \\
1000 \\
147\end{array}$}} \\
\hline & & & T cal. & 600 & 663 & 753 & 843 & 932 & & \\
\hline & & & sd & 59 & 60 & 74 & 96 & 121 & & \\
\hline & & \multirow{3}{*}{ Pressão média } & T fixa & 650 & 700 & 750 & 800 & 850 & \multirow{3}{*}{\multicolumn{2}{|c|}{$\begin{array}{c}900 \\
4.7 \\
0.82 \\
\end{array}$}} \\
\hline & & & $P_{\text {cal. }}$ & 3.0 & 3.4 & 3.7 & 4.0 & 4.4 & & \\
\hline & & & sd & 0.42 & 0.48 & 0.56 & 0.64 & 0.73 & & \\
\hline & & PT média & & \multicolumn{3}{|c|}{$\mathrm{T}=676^{\circ} \mathrm{C}, \mathrm{sd}=95$} & \multicolumn{4}{|c|}{$\mathrm{P}=3.0$ kbar, $\mathrm{sd}=0.8$} \\
\hline \multirow{7}{*}{$\begin{array}{c}\text { Gnaisse } \\
\text { Pelítico } \\
\text { VC 17-04 }\end{array}$} & & \multirow{3}{*}{ Temperatura média } & P fixa & 2.0 & 3.0 & 4.0 & 5.0 & 6.0 & \multirow{3}{*}{\multicolumn{2}{|c|}{$\begin{array}{c}7.0 \\
1020 \\
93\end{array}$}} \\
\hline & & & Tcal. & 611 & 716 & 821 & 926 & 1000 & & \\
\hline & & & sd & 34 & 34 & 35 & 49 & 71 & & \\
\hline & & \multirow{3}{*}{ Pressão média } & T fixa & 650 & 700 & 750 & 800 & 850 & \multicolumn{2}{|c|}{900} \\
\hline & & & P cal. & 2.6 & 3.0 & 3.3 & 3.7 & 4.0 & \multicolumn{2}{|c|}{4.4} \\
\hline & & & $r-1-1$ & 0.25 & 0.26 & 0.27 & 0.28 & 0.30 & \multicolumn{2}{|c|}{0.34} \\
\hline & & PT média & & $\mathbf{T}=$ & $6^{\circ} \mathrm{C}, \mathrm{s}$ & $=66$ & & $3.4 \mathrm{~kb}$ & $s d=$ & \\
\hline & & & P fixa & 2.0 & 3.0 & 4.0 & 5.0 & 6.0 & & \\
\hline Gnaisse & & Temperatura média & T cal. & 623 & 730 & 837 & 900 & 960 & & \\
\hline Pelítico & & & $-1-1$ & 33 & 32 & 32 & 45 & 63 & & \\
\hline VC 17-03 & & & T fixa & 650 & 700 & 750 & 800 & 850 & & \\
\hline & & Pressão média & P cal. & 2.5 & 2.9 & 3.2 & 3.6 & 4.0 & & \\
\hline & & & $\mathrm{Sd}$ & 0.28 & 0.24 & 0.25 & 0.26 & 0.28 & & \\
\hline & & PT média & & $T=$ & $0^{\circ} \mathrm{C}, \mathrm{s}$ & $=68$ & & $3.4 \mathrm{~kb}$ & $\mathbf{s d}=$ & \\
\hline Gnaisse Máfico & $\mathrm{Opx}+\mathrm{Cpx}+\mathrm{PI}$ & & P Kbar & 2 & 3 & 4 & 5 & 6 & $\mathrm{sdT}$ & $\mathrm{sdP}$ \\
\hline VC 02-18 & $+\mathrm{Qtz}+\mathrm{Bt}$ & en + hed $=f s+d i$ & $\mathrm{~T}^{\circ} \mathrm{C}$ & 606 & 605 & 605 & 605 & 605 & 218 & - \\
\hline SEGMENTO ARR & O CANHÂOO & & & & & & & & & \\
\hline Gnaisse Calcioss. & Grt+Cpx+Scpt & & P Kbar & 2 & 3 & 4 & 5 & 6 & sdT & $\mathrm{sdP}$ \\
\hline VC 05-05 & $\mathrm{Qtz}+\mathrm{Cal}$ & hed + cats $=$ grs + alm & $\mathrm{T}^{\circ} \mathrm{C}$ & 811 & 840 & 869 & 897 & 926 & 132 & 4.6 \\
\hline & & grstalm+cal+qz=hed +me & $\mathrm{T}^{\circ} \mathrm{C}$ & 680 & 734 & 787 & 839 & 892 & 84 & 1.5 \\
\hline SEGMENTO VÁR? & A DO CAPIVARI & & & & & & & & & \\
\hline Mármore Impuro & $\mathrm{Cpx}+\mathrm{Amph}+\mathrm{Cal}$ & & P Kbar & 2 & 3 & 4 & 5 & 6 & $\mathrm{sdT}$ & $\mathrm{SdP}$ \\
\hline VC 15-09 & $+\mathrm{phl}+\mathrm{Qtz}$ & ts $+d i+n a p h=t r+p a r g$ & & 785 & 799 & 813 & 826 & 852 & 196 & 15 \\
\hline
\end{tabular}


ral e microtectônica.

Nos gnaisses máficos os valores de temperatura obtidos para o equilibrio entre as fases revelaram-se inferiores aos obtidos no gnaisse pelítico com outros termômetros de troca, fornecendo temperaturas de $605 \pm 218^{\circ} \mathrm{C}$ para uma pressão fixa de $4 \mathrm{kbar}$. Isso ocorre porque os porfiroblastos de ortopiroxênio disponíveis nas amostras e utilizados para os cálculos de PT apresentam evidências de exsolução, estando em desequilíbrio, não representando, dessa forma, as composições do pico metamórfico.

Nos gnaisses calciossilicatados foram obtidas temperaturas de $840 \pm 132^{\circ} \mathrm{Ce} 734 \pm 84^{\circ} \mathrm{C}$ para $3 \mathrm{kbar}$ e de $869 \pm 132 \mathrm{e} 787 \pm 84^{\circ} \mathrm{C}$ para pressão fixa de $4 \mathrm{kbar}$. Essas temperaturas são compatíveis com as temperaturas de pico térmico obtidas nos gnaisses pelíticos.

Nos mármores impuros as reações traçadas forneceram temperaturas de $799 \pm 196^{\circ} \mathrm{C} \mathrm{e} 813 \pm 196^{\circ} \mathrm{C}$ para $3 \mathrm{e} 4 \mathrm{kbar}$, respectivamente. Os resultados obtidos nos mármores impuros situam-se dentro do intervalo de temperatura fornecido por outros geotermômetros nos diversos litotipos estudados.

DISCUSSÃO E SÍNTESE DOS RESULTADOS Os dados de termobarometria são compativeis com as paragêneses minerais em equilíbrio nos diferentes litotipos e permitem, em conjunto, caracterizar dois eventos termais principais na SMVC:

1. $\mathrm{M}_{1}$ - Evento com pico térmico de fácies anfibolito superior, com temperaturas variando entre 740 e $790^{\circ} \mathrm{C}$ e baixas pressões (3$4 \mathrm{kbar}$ ), caracterizando profundidade de 11 a $15 \mathrm{Km}$, utilizando valores de densidade médios para crosta continental (Thompson 1992). O metamorfismo $M_{1}$ atingiu localizadamente temperaturas de fácies granulito, como representado pela paragênese espinélio + silimanita nos metapelitos, escapolita rica em meionita nos gnaisses calciossilicatados e presença de ortopiroxênio nos gnaisses máficos. Esse evento é responsável pela geração da trama granoblástica de equilíbrio térmico estático $\left(\mathrm{S}_{1}\right)$.

2. $\mathrm{M}_{2}$ - Evento de metamorfismo retrogressivo, com paragêneses de fácies anfibolito médio, acompanhado de entrada de fluidos ricos em $\mathrm{H}_{2} \mathrm{O}$. Desenvolveu trama apenas nos mármores impuros e nas demais rochas levou à substituição localizada de minerais do metamorfismo $\left(\mathrm{M}_{1}\right)$ por minerais hidratados.

CONCLUSÕES Os resultados termobarométricos obtidos indi- cam que o metamorfismo $M_{1}$ caracteriza-se por temperaturas elevadas e pressões baixas, sendo que o sistema foi gradualmente empobrecido em $\mathrm{H}_{2} \mathrm{O}$. Essas condições indicam que o evento deformacional $\mathrm{D}_{1}$ ocorreu em condições de fácies anfibolito superior/granulito, caracterizando um terreno metamórfico de baixa P/ T(De Yoreo 1991).

A interpretação do ambiente tectônico do metamorfismo de baixa P/T no presente estudo foi limitada pela carência de paragêneses progressivas preservadas e dados geocronológicos que permitissem o estabelecimento da trajetória P-T-t desenvolvida nas rochas investigadas. Apesar dos fatores limitantes, o grande volume de intrusões cálcio-alcalinas (CGAR) associadas aos gnaisses da SMVC reforça a hipótese de que o metamorfismo $M_{1}$ tenha ocorrido em ambiente do tipo arco magmático.

Em regiões de arco magmático, o grande volume de intrusões e o alto fluxo de fluidos fornecem o calor advectivo durante o metamorfismo, assim como o espessamento crustal aumenta o aporte de calor por condução, elevando significativamente o fluxo térmico da região (De Yoreo 1991). A geoterma anômala resultante pode gerar altas temperaturas de metamorfismo em pressões relativamente baixas $( \pm 12 \mathrm{~km})$.

A inexistência de estudos geocronológicos na sequiência impossibilita o estabelecimento de uma idade exata para o metamorfismo $M_{1}$, mas resultados recentes (Silva et al. em preparação) indicam idades neoproterozóicas para o metamorfismo de fácies anfibolito superior/granulito.

O metamorfismo $\mathrm{M}_{2}$ que forma trama nos mármores impuros e é representado nos outros litotipos da sequiência pela hidratação restrita de minerais da paragênese mineral $\mathrm{M}_{1}$, podendo estar relacionado ao resfriamento e hidratação da sequiência no final da aglutinação brasiliana. Entretanto, é necessário adquirir dados geocronológicos do metamorfismo $\mathrm{M}_{1}$ e $\mathrm{M}_{2}$ que afetaram a SMVC para elucidar as relações entre a Suíte Metamórfica Várzea do Capivarita e as demais unidades dso Domínio Leste do Cinturão Dom Feliciano.

Agradecimentos Ao Projeto de Cooperação Internacional CAPES - British Council (081/98) e FAPERGS (ARD 98/1041.0). Aos revisores da $\mathrm{RBG}$ pelas sugestões ao manuscrito.

\section{Referências}

Ashworth J. R. \& McLellan E.L. 1985. Textures. In J. R. Ashworth (ed.) Migmatites. Glasgow. Blackie \& Son Limited, 180-203

Babinski M., Chemale Jr.F., Hartmann L.A., VanSchmus W.R., da Silva L.C. 1996. Juvenile accretion at 750-700 Ma in southern Brazil. Geology, 24:439-442

Babinski M., Chemale Jr.F., Hartmann L.A., Silva L.C., VanSchmus W.R. 1994. Discovery of Neoproterozoic juvenile accretion and crustal remobilization belts formed during the Brasiliano Cycle in Southern Brazil, based on U-Pb and Sm-Nd geochronology. J. Sou. Am. Ear. Sci. 8:3-4

Berg J.H. 1977. Regional geobarometry in the contact aureoles of the anorthositic Nain Complex, Labrador. J. Petrol., 18:399-430

Bucher K. \& Frey M. 1994. Petrogenesis of metamorphic rocks. 6 ed. Berlin, Springer \& Verlag, $318 \mathrm{p}$.

Carpenter M.A., Putnis A., Navrotsky A., McConnell J.D. 1983. Entalphy effects associated with Al/Si ordering in anhydrous Mgcordierite. Geoch. Cosmoch. Acta, 47:899-906
Chemale Jr.F., Hartmann L.A., Babinsky M., Wildner W., VanSchmus W.R. 1995. Stratigraphy and tectonism of Precambrian to early Paleozoic units in the Southern Brazil and Uruguay. Acta Geol. Leopold., 44:1-11

Costa A.F.U. 1997. Modelagem geofisica da estruturação das associações petrotectônicas do Escudo Sul-rio-grandense. Instituto de Geociências, Universidade Federal do Rio Grande do Sul, Porto Alegre, Tese de Doutoramento, 274 p.

Costa A.F.U., Ramgrab G.E., Fernandes L.A.D., Camozzato E., Azevedo M.L.V. 1995. Compartimentação tectônica das associações de rochas pré-cambrianas do Escudo Sul-rio-grandense baseada em dados de magnetometria e gravimetria. In: SBG, V Simpósio Nacional de Estudos Tectônicos, Gramado, Resumos Expandidos, 236-238

Currie K.L. 1974. A note on the calibration of the garnet-cordierite geothermometer and geobarometer. Contr. Mineral. Petrol., 44:3544

Silva L.C., Hartmann L.A., McNaughton N.J., Fletcher I.R. 1999 
SHRIMP U $\mathrm{Pb}$ zircon dating of Neoproterozoic granitic magmatism and collision in the Pelotas Batholith, southernmost Brazil. Intern. Geol. Revi., 41:531-551

Silva L.C., Hartmann L.A., McNaughton N.J., Fletcher I.R. 2000. Zircon U-PbSHRIMP dating of a Neoproterozoic overprint in Paleoproterozoic granitic-gneissic terranes, southern Brazil. Am. Mineral., 85:649-667

De Yoreo J.J., Lux D.R., Guidotti C.V. 1991. Thermal modelling in lowpressure/high temperature metamorphic belts. Tectonoph., 18:209238

Deer W.A., Howie R.A., Zussmann J. 1992. An introduction to the rockforming minerals. 2 ed. London, Longsman, 560p.

Droop G.T.R. \& Al-Filali I.Y. 1996. Interactions of aqueous fluids with calcareous metassediments during high-T, low-P metamorphism in Quada area, southern Arabian Shield. J. Metam. Geol., 14:613-634

Eggert R.G. \& Kerrick D.M. 1980. Hydrothermal experiments in the system $\mathrm{CaO}-\mathrm{MgO}-\mathrm{SiO}$ (sub2) $\mathrm{CO}$ (sub2) - $\mathrm{H}$ (sub2) $\mathrm{O}$ and petrologic implications for high pressure metamorphosed siliceous dolomites. Abstracts with Programs, GSA, 12:420

Ellis D.E. 1978. Stability and phase equilibria of chloride and carbonate bearing scapolites at $750^{\circ} \mathrm{C}$ and $4000 \mathrm{bar}$. Geoch. Cosmoch. Acta, 42: $1271-1281$

Fernandes L.A.D., Koester F., Porcher C.C., Menegat R., Costa AF.U., Caravaca G., Masquelin E., Silva A.O.M., Soliani Jr. E. 2001. Tectonic Evolution of the Dom Feliciano Belt in southern Brazil: a critical review. Gondw. Res., (submetido)

Fernandes L.A.D. e Koester E. 1999. The Neoproterozoic Dorsal the Canguçu strike-slip shear zone: its nature and role in the tectonic evolution of southern Brazil. J. Afr. Ear. Sci., 29:3-24

Fernandes L.A.D., Menegat R., Costa A.F.U., Porcher C.C., Tommasi A., Kraemer G., Rambgrab G.E., Camozzato E. 1995a. Evolução tectônica do Cinturão Dom Feliciano no Escudo Sul-rio-grandense: uma contribuição a partir do registro geológico. Rev. Bras. Geoc., 25:351-374

Fernandes L.A.D., Menegat R., Costa A.F.U., Porcher C.C., Tommasi A., Kraemer G., Rambgrab G.E., Camozzato E. 1995b. Evolução tectônica do Cinturão Dom Feliciano no Escudo Sul-rio-grandense: uma contribuição a partir das assinaturas geofísicas. Rev. Bras. Geoc., 25:375-384

Fernandes L.A.D., Tommasi A., Porcher C.C. 1990. Esboço estrutural de parte do Batólito de Pelotas - região de Quitéria-Capivarita. Acta Geol. Leopold., 13:117-138

Fernandes L.A.D., Tommasi A., Porcher C.C. 1992. Deformation patterns in the Southern Brazilian Branch of the Pan-African Dom Feliciano belt. J. Sou. Am. Ear. Sci., 5:77-96

Ferry J.M. \& Spear F.S. 1978. Experimental calibration of the partitioning of the Fe and $\mathrm{Mg}$ between biotite and garnet. Contr: Min. Petrol., 66: 113-117

Frantz J.C., Lima E.F., Pinheiro Machado R., Naumann M.P. 1984. Contribuição à geologia da região de Encruzilhada do Sul, RS. In SBG, Congresso Brasileiro de Geologia, 33, Rio de Janeiro, Anais, 2407-2416

Frisch T. 1988. Reconnaissance geology of the Precambrian Shield of Ellesmere, Devon and Coburg islands, Canadian Arctic Archipelago. Memoir, Geol. Sur. Can., 409; 102p.

Ganguly J. \& Saxena S.K. 1984. Mixing properties of aluminosilicate garnets: constraints from natural and experimental data, and applications to geothermobarometry. Am. Mineral., 69:88-97

Goldsmith J.R. \& Newton R.C. 1977. Scapolite-plagioclase stability relations at high pressure and tenperatures in the system $\mathrm{NaAlSi}_{3} \mathrm{O}_{8}$ $\mathrm{CaAlSi} \mathrm{O}_{8}-\mathrm{CaCO}_{3}-\mathrm{CaSO}_{4}$. Am. Mineral, , 62:1063-81

Graziani, G. \& Lucchese S. 1982. The termal behaviour of scapolites. Am. Mineral., 67:1229-1241

Guidotti C.V. 1984. Micas in metamorphic rocks. In: S.W. Bailey (ed.), Micas, p.357-467. Reviews in Mineralogy, 13. Mineralogical Society of America, Whashington, D.C

Harley S.L. \& Buick I.S. 1992. Wollastonite-scapolite assemblages as indicators of granulite pressure-temperatures-fluid historie, the Rauer Group, east Antartica. J. Petrol., 33:693-728

Hartmann L.A. 1998. Deepest exposed crust of Brazil - Geochemistry of Paleoproterozoic depleted Santa Maria Chico Granulites. Gond. Res. 1:331-341

Holdaway M.J. \& Lee S.M. 1977. Fe-Mg cordierite stability in highgrade pelitic rocks based on experimental and natural observations. Contr. Mineral. Petrol., 63:175-198

Holdaway M.J. 1976. Mutual compatibility relations of the $\mathrm{Fe}^{+2}-\mathrm{Mg}-$ Al silicates at $800^{\circ} \mathrm{C}$ and $3 \mathrm{~kb}$. Am. J. Sci., 276:285-308

Holland T.J.B. \& Powell R. 2001. Calculation of phase relations involving haplogranitic melts using an consistent thermodynamic data Set. $J$. Petrol., 42:673-681

Holland T.J.B. \& Powell R. 1998. An Internally Consistent Thermodynamic Data Set For Phases of Petrological Interest. $J$. Metam. Geol., 16:309-343.

Kas H.R. \& Metz P. 1980. Experimental investigation of the metamorphism of siliceous dolomites. Contr. Mineral. Petrol., 73:151159

Kars H., Jansen J.B.H., Tobi A.C., Poorter R.P.E. 1980. The metapelitic rocks of the polymetamorphic Precambrian of Rogaland, SW Norway - Part II. Mineral relations between cordierite, hercynite and magnetite within the osumilite isograd. Contr: Mineral. Petrol., 74:235-244

Kretz F. 1994. Metamorphic Cristallization. West Sussex, Jonh Wiley \& Sons Ltd, 507p.

Lal R.K., Ackermand D., Seifert F. \& Haldar S.K. 1978. Chemographic relationships in sapphirine-bearing rocks from Sonapahar, Assam, India. Contr. Mineral. Petrol., 67:169-187

Leake B. 1978. Nomenclature of amphiboles. Am. Mineral., 63:10231052

Leite J.A.D., Hartmann L.A., Fernandes L. A.D., McNaughton N.J., Soliani Jr.E., Koester E., Santos J.O.S., Vasconcellos M.A.Z. 1998. Zircon U-Pb zircon geochronology of Neoproterozoic juvenile and crustal reworked terranes in southernmost Brazil. Intern. Geol.Revi., 40:688-705

Leite J.A.D., Hartmann L.A., Fernandes L.A.D, McNaughton N.J., Soliani E., Koester E., Santos J.O.S., Vasconcellos M.A.Z. 2000. Zircon U$\mathrm{Pb}$ SHRIMP dating of gneissic basement of the Dom Feliciano Belt, southernmost Brazil. J. Sou. Am. Ear. Sci., 13:739-750

Lepezin G.G. \& Melenevsky V.N. 1977. On problem of water diffusin in the cordierites. Lithos, 10:49-57

Metz P. 1976. Experimental investigation of the metamorphism of siliceous dolomites; III, Equilibrium data for the reaction, 1 tremolite +11 dolomite $\hat{U} 8$ forsterite +13 calcite $+9 \mathrm{CO}$ (sub2) $+1 \mathrm{H}$ (sub2) $O$ for the total pressures of 3,000 and 5,000 bars. Cont. Mineral. Petrol., 58:137-148

Metz P., Puhan D., Winkler H.G.F. 1968. Equilibrium reaction on the formation of talc an tremolite by metamorphism of siliceous dolomites. Naturwissenschaften, 55:225-226

Porcher, C.C. \& Fernandes L.A.D. 1990. Relações embasamento/"cobertura" na porção ocidental do Cinturão Dom Feliciano: um esboço estrutural. Pesquisas, 17:72-84

Porcher C.C., McNaughton N.J., Hartmann L.A. (submetido) Geochronology of proterozoic basement-cover relatioship in the southern Brazilian Porongos belt. Prec. Res.

Schenk V. 1984. Petrology of felsic granulites, metapelites, metabasics, ultramafics and metacarbonates from southern Calabria (Italy). $J$. Petrol., 25:255-298

Schereyer W. 1965. Zur stabilitat des ferrocordierits. Beitr. Mineral. Petrol. 11:297-322

Shaw D.M. 1960. The geochemistry of scapolite - Part 2, Trace elements, petrology and general geochemistry. J. Petrol., 1:261-285 
Soliani Jr.E. 1986. Os dados geocronológicos do escudo sul-rio-grandense $e$ suas implicações de ordem tectônica. Instituto de Geociências, Universidade Federal do Rio Grande do Sul, Porto Alegre, Tese de Doutoramento, $298 \mathrm{p}$.

Spear F.S. 1993. Metantorphic phase equilibria and pressure-temperaturetime paths. 1ed. Whashington, BoockCrafters, $799 \mathrm{p}$.

Spear F.S. 1991. On the interpretation of peak metamorphic temperatures in light of garnet diffusion during cooling. J. Metam. Geol., 9:379-388

Spear F.S. 1981. An experimental study of hornblende stability and compositional variability in amphibolite. Am. J. Sci., 281:697-734

Spear F.S. \& Florence F.P. 1992. Thermobarometry In Granulites - Pitfalls And New Approaches. Prec. Res., 55:209-241

Thompson A.B. 1992. Metamorphism and Fluids. In G.C. Brown, C.J. Hawkesworth \& R.C.L. Wilson (ed.) Understanding the Earth. Cambridge, University Press, 222-228

Tommasi A. 1991. Evolução cinemática do Cinturão Dom Feliciano durante o Ciclo Brasiliano. Instituto de Geociências, Universidade Federal do Rio Grande do Sul, Porto Alegre, Dissertação de Mestrado, $215 \mathrm{p}$.

Wood B.J. 1973. $\mathrm{Fe}^{+2}+\mathrm{Mg}^{+2}$ partition between coexisting cordierite and garnet - a discussion of the experimental data. Com. Miner. Petrol., 40:253-258

Whittington A., Harris N., Baker J. 1998. Low-pressure crustal anatexis:the significance of spinel and cordierite from metapelitic assemblages at Nanga Parbat, northern Pakistan. In P. J. T. \&. P. J. O'Brien (ed.) What drives metamorphism and metamorphic reaction? London: The Geological Society of London, 183-193

Manuscrito A-1247

Recebido em 2 de agosto de 2001

Revisão dos autores em 15 de outubro de 2002

Revisão aceita em 20 de outubro de 2002 